\title{
ELECTROCARDIOGRAPHY IN MITRAL VALVULAR DISEASE
}

\author{
BY \\ HUGH R. L. FRASER AND RICHARD TURNER
}

From the Department of Medicine, University of Edinburgh, and the Cardiac Department, Western General Hospital Edinburgh

Received March 3, 1955

The introduction of surgical treatment for valvular heart disease demands meticulous attention to detail in all aspects of the assessment. A number of studies have been made on the electrocardiographic changes that occur in patients with rheumatic heart disease and their relationship to clinical and pathological findings but many were before the introduction of multiple chest leads.

We have made an electrocardiographic study of mitral valvular disease in a series of patients subjected to operation and in a series of post-mortem cases in all of whom detailed clinical, radiological, and usually cardiac catheterization studies were available. The opportunity has been taken to review the generally accepted criteria for right ventricular hypertrophy (R.V.H.) in the light of this experience, and the cardiographic changes have been related to the clinical findings, special investigations, and operative findings in order to decide the practical value of electrocardiography in the assessment of patients for valvotomy.

\section{MATERIAL AND Methods}

There were 200 patients in the operation series. Of these, 177 had pure or predominant mitral stenosis and were treated by valvotomy and 23 had predominant mitral incompetence and most of them were treated by valvoplasty. Sixty also had aortic incompetence, 3 aortic stenosis, and 15 essential hypertension (B.P. $>160 / 100$ ) in varying degree. Some had more than one complication.

There were 38 cases in the post-mortem series. Of these 25 had pure or predominant mitral stenosis and 13 had predominant mitral incompetence. Twelve of them had also aortic incompetence, 6 aortic stenosis, and 3 essential hypertension in varying degree. Some had more than one complication.

In addition, we have examined the cardiograms in 2000 consecutive patients (excluding the present series) in whom a full series of leads had been recorded to assist the evaluation of certain abnormal features in the operative and post-mortem series.

Standard and augmented unipolar limb leads, together with præcordial leads V1-V7 and CR1, were taken in all the 200 operation cases and in 36 of the 38 post-mortem cases. Right-sided V leads were also recorded in 141 cases. Each lead was individually standardized to give a deflection of $10 \mathrm{~mm}$. for $1 \mathrm{mv}$. difference of potential. All records were made with the patient recumbent.

The following points were studied: axis deviation, algebraical sum of $R+S$ in lead I, electrical position of heart; $P$ waves, $Q-T$ and $P-R$ intervals; absolute height of $R$ and of $S$ and the $R / S$ ratio in $V 1$ and $V 2$, CR1, V5 and V6, V3R, V4R and VE; $Q$ waves; height of $R$ and $R / Q$ ratio in $A V R$; flattening or inversion of $\mathrm{T}$ and depression of S-T segment in V1, V2, V5, V6; patterns of right bundle branch block; and ventricular activation time.

\section{STANDARD LimB LEADS}

The amount of useful information obtainable from standard limb leads alone is limited. The absence of any cardiographic abnormality suggests that the degree of underlying valvular disease is probably slight 
but reliance cannot be placed on this because 9 patients in sinus rhythm with significant mitral disease had normal standard leads apart from minor changes in the $P$ waves. In 21 auricular fibrillation was the only abnormality. Broad or bifid $\mathbf{P}$ waves of the type described below are strongly suggestive of mitral disease. Signs of R.V.H. in præcordial leads were present in 11 cases in which there was not even suggestive evidence of this in the standard limb leads. In the past, right axis deviation with negative $T$ waves in standard limb leads II and III was considered the classical pattern of R.V.H. This was present in only 34 of the present series of 115 cases in which R.V.H. was diagnosed electrocardiographically. Myers et al. (1948) have emphasized that the pattern does not necessarily signify R.V.H. and that with a vertical heart may occur in normals or even with left ventricular hypertrophy (L.V.H.). Likewise changes due to L.V.H. may be present only in the præcordial leads.

Axis deviation can be calculated and is discussed below. Right axis deviation associated with auricular fibrillation or with bifid $P$ waves of the type described below by itself strongly suggests the presence of mitral stenosis. Finally the presence and nature of an arrhythmia may be confirmed or disclosed.

\section{Axis Deviation}

The electrical axis of the heart can be calculated from the standard limb leads with reference to Einthoven's triangle. For convenience we have used the method described by Dieuaide (1921) and recommended by Ashman and Hull (1941). The limitations of axis deviation as a guide to ventricular hypertrophy have long been recognized but nevertheless deviations from the normal range are of clinical value and may serve to indicate the need for recording other leads or in cases of mitral stenosis as a warning that some significant complication is present. The upper limits of normal for axis deviation in adults have been placed at $90^{\circ}$ by Burch and Winsor (1949) and at $92^{\circ}$ by Ashman and Hull (1941). Both authors refer to rare exceptions. Carouso et al. (1951) found that 99 per cent of normal people have an axis of less then $90^{\circ}$. In our series axis deviation was divided into four grades: (1) under $90^{\circ}=120$ cases; (2) $90-99^{\circ}=35$ cases; (3) $100-109^{\circ}=$ 25 cases; and (4) $110^{\circ}$ or over $=20$ cases. All those in Group 4, 20/25 in Group 3, and 23/35 in Group 2 had signs of R.V.H. in the præcordial leads. Since signs of R.V.H. were present in 89 per cent of cases in which R.A.D. $>100^{\circ}$ this degree of R.A.D. in itself strongly suggests that R.V.H. is present. The converse does not hold because signs of R.V.H. were present in 49 out of $120(41 \%)$ patients with R.A.D. $<90^{\circ}$. On the other hand there was no close correlation between the degree of R.A.D. and the severity of the R.V.H. pattern.

In the majority of cases the correlation between the degree of R.A.D. as calculated and the algebraical sum of $\mathbf{R}+\mathrm{S}$ in lead I was close. However, axis deviation is calculated by plotting the algebraical sum of $R+S$ in lead I against the algebraical sum of $R+S$ in lead III. III is an unreliable lead in that it is influenced by body build and in particular by the height of the diaphragm. It sometimes happens that when from examination of lead I considerable R.A.D. can be expected, i.e. by a small or absent $R$ and a significant $S$, these findings are, so to speak, neutralized by a tall $\mathbf{R}$ in lead III.

We, therefore, compared the algebraical sum of $R+S$ in lead I with R.A.D. calculated in the usual manner and correlated this figure, which is simply obtained, with evidence for R.V.H. in the chest leads. In each of 33 cases in which $R+S$ in lead I amounted to $-3 \mathrm{~mm}$., in 7 of 11 cases when it was -2 and in 16 of 25 in which it was -1 , signs of R.V.H. were present.

It is concluded, therefore, that in patients with mitral stenosis, an algebraical sum of the $R$ and $S$ waves in standard lead I amounting to $-3 \mathrm{~mm}$. or less can be taken as strong presumptive evidence for R.V.H.

\section{The Electrical Position of the Heart}

The determination of the electrical position of the heart can be made according to the criteria published by Wilson et al. (1946) or by Goldberger (1953). However, these authors express their conclusions in different terms and we have found that the cardiograms of some of our patients cannot be fitted into groups described by either of them. Many workers refer to the electrical position of the heart without stating the criteria on which the assessment has been made. Familiarity with the electrical position is necessary for a full understanding of all the various patterns, but in our opinion is not of practical value except in the detection of biventricular hypertrophy and in the elucidation of atypical patterns that might otherwise be misinterpreted. We have mainly confined our attention to the determination of whether the heart is in a "vertical", " horizontal", "intermediate" or "indeterminate" position, and to the estimation of the degree of rotation round a longitudinal axis, i.e. clockwise or anti-clockwise as viewed from below. 
According to Goldberger (1953) a QS, $\mathrm{rS}$ or $\mathrm{rSr}^{\prime}$ pattern in V1, signifies a vertical heart, and a $\mathrm{qR}$ or QR pattern in VL a horizontal heart. Wilson (1946) classifies the patterns as follows:

Vertical heart.-VF resembles V5 and V6, and VL resembles V1 and V2.

Semi-vertical heart.-VF resembles V5 and V6, and in VL, QRS is small.

Horizontal heart.-VL resembles V5 and V6, and VF resembles V1 and V2.

Semi-horizontal heart.-VL resembles V5 and V6, and in VF, QRS is small.

Intermediate position.-VL and VF both resemble V5 and V6.

When R.V.H. is present the heart is usually vertical, leads V1 and V2 show an R or Rs pattern and therefore will not resemble the pattern in VL so that Wilson's criteria for the diagnosis of a vertical heart are unlikely to be fulfilled and under these circumstances are inappropriate. The explanation lies in the fact that Wilson's classification only considers rotation round the longitudinal and transverse axes.

In the combined operation series of 200 patients the heart was vertical or semi-vertical in 176, horizontal or semi-horizontal in 14, and intermediate or indeterminate in position in 10 . In 90 per cent of the 177 patients with predominant stenosis the heart was vertical or semi-vertical, but of the 23 with predominant incompetence it was vertical or semi-vertical in 17, horizontal or semi-horizontal in 3 and indeterminate or intermediate in 3.

In the 14 patients in whom the heart was horizontal or semi-horizontal, and in the 10 in whom it was indeterminate or intermediate, some factor complicating mitral stenosis was usually present, e.g. mitral incompetence, aortic valvular disease, or obesity. In two the electrical position of the heart was an important factor in the diagnosis of biventricular hypertrophy as discussed below. Apart from its usefulness in this respect it is concluded that the electrical position of the heart is of little practical value in assessing the predominant defect at the mitral valve.

Clockwise Rotation. Clockwise rotation is usually diagnosed when the $\mathbf{S}$ normally present in V1-V3, persists as far round as V5 or V6 and aVR shows a QR pattern. The deeper the $S$ or the greater the $S / R$ ratio in leads over the left ventricle and the taller the $R$ and the bigger the $R / Q$ ratio in aVR, the greater the degree of clockwise rotation but in our experience these two signs by no means always accompany each other and we are uncertain as to the precise mechanism and relative significance of each.

Clockwise rotation is a matter of degree and is not uncommon in normal hearts. Extreme clockwise rotation usually signifies R.V.H. but there is no dividing line that separates with certainty physiological from pathological rotation. Nevertheless, there is general agreement that $S>R$ in V5 and $R>Q$ in aVR is abnormal. Similarly there are no absolute values for diagnosing an abnormal depth of S in V5 or an abnormal height of $\mathrm{R}$ in aVR.

From a detailed analysis of our material it is concluded that $S>R$ in $V 5$, or $R>Q$ in aVR, and a depth of $S$ in $V 5$ of $5 \mathrm{~mm}$. or more or a height of $R$ in aVR of $3 \mathrm{~mm}$. or more provide strong presumptive evidence for R.V.H.

TABLE I

INCIDENCE AND SignificANCE OF INDIRECt Signs of R.V.H.

\begin{tabular}{l|c|c|c|c}
\hline \multicolumn{2}{c|}{ Indirect Signs } & \multicolumn{2}{c}{ Direct Signs } \\
\cline { 1 - 2 } Sign & Lead & $\begin{array}{c}\text { No. of } \\
\text { Cases }\end{array}$ & $\begin{array}{c}\text { No. of } \\
\text { Cases }\end{array}$ & Percentage \\
\hline R.A.D. $=110^{\circ}$ or more & I and III & 20 & 20 & 100 \\
R.A.D. $=100^{\circ}-109^{\circ}$ & I and III & 25 & 20 & 80 \\
R+S=-3 mm. or less & I & 33 & 33 & 100 \\
R/Q $>1$ & aVR & 28 & 28 & 100 \\
R=3 mm. or more & aVR & 42 & 38 & 89 \\
S/R $>1$ & V5(6) & 23 & 23 & 100 \\
S=5 mm. or more & V5(6) & 46 & 41 & 89 \\
& & & & \\
\hline
\end{tabular}

\section{P WAVES}

The upper range of normal for $\mathbf{P}$ wave height in the standard limb leads has been taken by various authors as $2 \cdot 5-3 \mathrm{~mm}$. and for breadth $0 \cdot 1-0 \cdot 12 \mathrm{sec}$. Broad, notched, or bifid $P$ waves have long been recognized as a characteristic feature in patients with mitral valvular disease ( $P$ mitrale) and when pronounced in degree are almost diagnostic (Fig. 1). They were present in 106 of the 115 patients in sinus rhythm (92\%). Presumably they result from atrial hypertrophy secondary to the mechanical results of mitral stenosis because frequently we have observed regression following successful valvotomy (Fig. 2). Reynolds (1953) suggests that the first peak of the bifid $P$ wave derives from the right atrium and the second peak from 


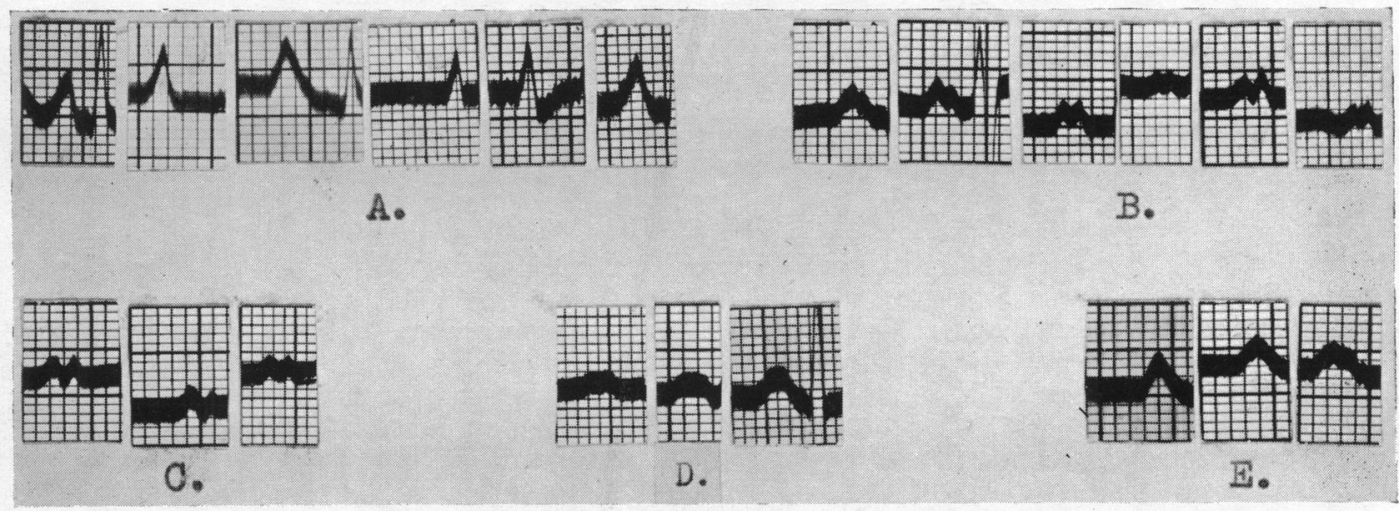

Fig. 1.-Abnormal $P$ waves. (A)-(E). Different types.

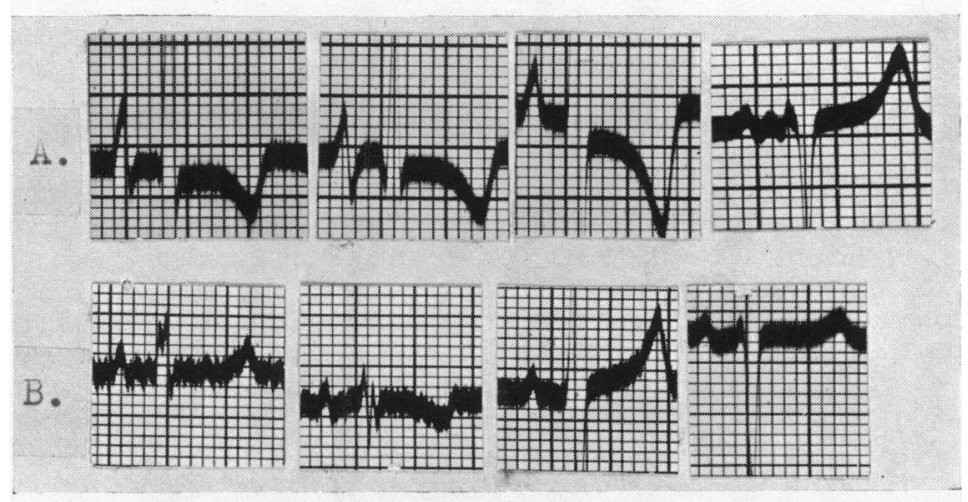

Fig. 2.-Regression of abnormal $P$ wave patterns following valvotomy.

(A) Before operation. (B) After operation.

the left atrium. Broad and slightly notched $P$ waves may be seen in hypertensive heart disease and Leatham (1950) reported slight notching in 17 per cent of his 100 normal cases although it was never pronounced. These observations make it impossible to be certain that such minor changes are pathological in a case of mitral valvular disease. Precise criteria cannot be laid down but in our consecutive series of 2000 unselected cardiograms we have observed marked changes such as those depicted in Fig. 1(B-E) in only two patients without mitral valvular disease: in neither was there a satisfactory explanation. In the operation series $P$ waves taller than $3 \mathrm{~mm}$. occurred in only 28 cases (14\%). Tall, spiked $P$ waves are commonly taken to indicate hypertrophy or dilatation of the right atrium and to be a particular feature of pulmonary and of congenital heart disease. In our series of patients with mitral disease $\mathbf{P}$ waves of this type were noted in 26 cases particularly in lead CR1 but there was no correlation between such $P$ waves and the size of the right atrium, the degree of pulmonary hypertension or of R.V.H., and they were often associated with bifid $\mathbf{P}$ waves in other leads. They were not a constant feature even in those with tricuspid disease. $\mathbf{P}$ waves broader than $0.12 \mathrm{sec}$. occurred in only 10 cases. The occurrence and degree of severity of these abnormal $\mathbf{P}$ waves were compared with the size of the two atria, the degrees of mitral stenosis and incompetence, and the severity of pulmonary hypertension but there was no close or useful correlation. This is not perhaps surprising since atrial hypertrophy is presumably related to the duration as well as the degree of mitral valvular disease and may be present in the absence of radiological enlargement. In 11 instances abnormal $\mathbf{P}$ waves were recorded only in the præcordial leads. It is noteworthy that the only three patients with normal $\mathbf{P}$ waves in all leads had relatively mild pulmonary hypertension and mitral stenosis. However, there were 3 others with tight stenosis and considerable pulmonary hypertension who had normal $\mathbf{P}$ waves in the standard limb leads but those in the chest leads were abnormal. 
The frequency with which abnormal $P$ waves occurred in the various leads was analysed and also the leads in which the abnormalities were best shown. Their occurrence was so variable and their relationship to other features in the assessment so uncertain that these results are not presented in tabular form; and it is not profitable to discuss them in any detail. It should be mentioned that abnormal $\mathbf{P}$ waves of similar type occurred in 11 out of 12 patients in sinus rhythm who were operated on for predominant mitral incompetence. In most of the cases of mitral stenosis that we have regarded as too mild for surgical treatment, normal $\mathbf{P}$ waves have been present.

It is concluded that broad, notched $P$ waves (especially in association with right axis deviation) are strongly suggestive of mitral disease and that entirely normal $P$ waves are unlikely to be associated with severe stenosis but that a detailed analysis of $P$ wave changes and the leads in which they occur is not of practical value in the assessment of patients for operation.

\section{Q-T AND P-R INTERVALS}

Prolongation of the Q-T and $\mathbf{P}-\mathbf{R}$ intervals in patients with rheumatic heart disease is commonly accepted as a sign of activity.

$Q-T$ Interval. This was measured in leads I or II according to which showed the most clearly defined end of the $T$ wave. Generally lead II was better than lead I for this purpose. Six successive cardiac cycles were analysed, the measurements being taken with the help of a $\times 6$ lens. For each pair of cycles the Q-T and R-R intervals were measured and from this the QTc estimated (see below). The average of the five QT $c$ intervals obtained was taken as the final measurement. In cases with sinus arrhythmia, in view of the variation in $R-R$ intervals, 12 successive cardiac cycles were analysed. Cases with auricular fibrillation were excluded from this analysis in view of the variation in $\mathbf{R}-\mathbf{R}$ intervals in most cases, the common difficulty in defining the end-point of $T$ waves because of $f$ waves interrupting the base line, and also because most of these cases were fully digitalized. Any case in whom salicylates, quinidine, or digitalis was being given was also excluded since these drugs are known to affect the QTc.

Correction of Q-T interval for heart rate was done by means of a nomogram based on Taran and Szilagyi's (1947) modification of Bazett's formula, $K=Q-T / c$ where $c=$ cycle length and $K=$ corrected QT, i.e. QTc. Ashman and Hull's (1941) criteria for the upper limit of the normal QTc were used in this series, i.e. 0.422 sec. for men and children and $0.432 \mathrm{sec}$. for women. Prolongation of QT $c$ was present in 21 cases of the 115 in sinus rhythm, and the degree of this was as follows: $0.005 \mathrm{sec}$. or less in 4, 0.01 sec. or less in $11,0.02 \mathrm{sec}$. or less in 17 , and greater than $0.02 \mathrm{sec}$. in 4 cases.

Two cases had clinical evidence of rheumatic activity within a few months prior to operation, and the QT $c$ was prolonged in one of them. Fourteen cases showed suggestive clinical evidence of rheumatic activity shortly after operation, and the QT $c$ was prolonged in 3 of these pre-operatively and 7 postoperatively.

Twenty-seven cases in normal rhythm showed Aschoff bodies in the operative biopsy of the left auricle, and of these 5 had prolongation of QTc. A further 28 cases in normal rhythm showed cellular aggregates that were in various degrees of development and were accepted by the pathologist as indicating active rheumatism, although not amounting to the classical Aschoff body. Of these 28 cases, 7 had prolongation of QT $c$ at the time of operation.

In 9 cases with prolongation of QT $c$ at the time of operation there were no clinical signs of active rheumatism prior to or following operation and the biopsy was negative. In the operation series we found that positive biopsies of the left auricle for active rheumatism occurred twice as commonly in the 39 cases that developed post-operative auricular fibrillation as compared with those that did not. Only 5 of these cases had prolongation of QT $c$ at the time of operation.

$P-R$ Interval. Of the 16 cases with clinical evidence of active rheumatism a few months before or shortly after operation, prolongation of $\mathbf{P}-\mathbf{R}$ interval occurred in only one. $\mathbf{P}-\mathbf{R}$ interval was prolonged in only one of the 27 cases showing Aschoff bodies in the auricular biopsy, and in 2 of the 28 cases showing less clearly developed histological features of active rheumatism. Six cases had prolongation of $\mathbf{P}-\mathbf{R}$ interval at the time of operation in whom there were no signs of active rheumatism prior to or following operation.

In only two cases were both the P-R interval and QT $c$ prolonged at the time of operation: neither had clinical evidence of active rheumatism in the six months before operation or after operation, and one case had a negative and the other a positive left atrial biopsy without definite Aschoff bodies. These findings demonstrate the inadequacy of the $Q-T$ and $P-R$ intervals in assessing rheumatic activity. 


\section{Right Ventricular HyPertrophy}

It is one of the main purposes of this paper to discuss the electrocardiographic signs of right ventricular hypertrophy (R.V.H.) because we have found that they usually signify the existence of considerable pulmonary hypertension, and that unless improvement can be obtained by operation, the outlook is poor. In the great majority of cases of rheumatic heart disease R.V.H. is secondary to tight mitral stenosis but occasionally, when pulmonary resistance is high, R.V.H. has been found in association with predominant mitral incompetence.

There have not been many papers that discuss criteria for the diagnosis of R.V.H. and none of the authors distinguish patterns produced by rheumatic heart disease from those secondary to other causes such as congenital heart disease and cor pulmonale. In rheumatic heart disease, not only is R.V.H. usually less severe than in these other conditions but in addition the mitral stenosis usually responsible for it is frequently complicated by co-existing mitral incompetence, aortic valvular disease, or rheumatic myocarditis, all of which may modify the cardiogram.

The electrocardiographic diagnosis of R.V.H. in patients in this series was primarily based on the criteria suggested by Wilson (1947), by Myers et al. (1948), by Sokolow and Lyon (1949 $a$ and $b$ ), and by Carouso et al. (1951) and subsequently modified in the light of the analysis of our own clinical and post-mortem material. We have also taken into account analyses of normal unipolar cardiograms by Sokolow and Friedlander (1949), by Leatham (1950), and the authors quoted in Nomenclature and Criteria for Diagnosis of Diseases of the Heart and Blood Vessels (1953), and in our own department. Justification for the criteria accepted rests on presumptive evidence for R.V.H. based on clinical, radiological, and catheterization studies; and on regression of the various patterns following valvotomy and post-mortem correlation. The cardiogram was frequently normal in patients who on other grounds might be expected to have R.V.H. and in the post-mortem series there were 13 patients with R.V.H. anatomically but no evidence of this electrocardiographically. These matters are discussed below, but first it would seem appropriate to give the grounds on which a presumptive diagnosis of R.V.H. was made.

\section{Presumptive Evidence for Right Ventricular Hypertrophy}

(1) Palpable right ventricular thrust.

(2) Marked accentuation of pulmonary second sound.

(3) Marked enlargement of the pulmonary artery.

(4) Radiological signs of right ventricular enlargement.

(5) Considerable pulmonary hypertension.

Review of Published Criteria. Wilson et al. (1944) in their paper on the præcordial cardiogram in R.V.H. stated that in leads from the right side of the chest the $\mathrm{R}$ wave is large, $\mathrm{Q}$ frequently present, $S$ usually absent, and $T$ deflections commonly inverted. In leads from the left side of the præcordium the $\mathrm{R}$ deflections are abnormally small and the $\mathrm{S}$ deflections abnormally large. In other words, the præcordial electrocardiogram is the reverse of that obtained when the heart is normal. It is clear from our experience that this is the fully developed electrocardiographic pattern of R.V.H. Myers et al. (1948) analysed 40 cases of R.V.H. confirmed anatomically, 13 of which were due to mitral stenosis; they accepted the same criteria referred to above but do not give any absolute measurements. In 3 cases signs of R.V.H. were present in V3R only and in 2 in VE only. Complete or incomplete right bundle branch block were accepted as presumptive evidence for R.V.H. Sokolow and Lyon (1949) discuss 65 cases of R.V.H. diagnosed clinically. Absolute criteria for R.V.H. were laid down as follows: $\mathrm{R}$ wave $>7 \mathrm{~mm}$. or $\mathrm{R} / \mathrm{S}$ ratio $>1$ in leads recorded over the right ventricle; $\mathrm{S} / \mathrm{R}>1$ in leads recorded over the left ventricle; $\mathrm{R}$ in $\mathrm{V} 1+\mathrm{S}$ in $\mathrm{V} 5>10.5 \mathrm{~mm}$.; $\mathrm{R} / \mathrm{S}$ in V5 divided by $\mathrm{R} / \mathrm{S}$ in $\mathrm{V} 1<0.4$. However, only 6 cases were due to mitral stenosis. The authors state that the diagnosis was made on clinical and radiological examination but make no reference to severity or to presumptive evidence for R.V.H. on other grounds. Carouso et al. (1951) analysed 58 post-mortem cases of which 24 were due to mitral stenosis. The R/S ratio was 
$>1$ in V1 and $<1$ in V5 in 19 cases; $>1$ in V1 and normal in V5 in 11 cases; normal in V1 and $<1$ in V5 in 14 cases. In 14 cases the $R / S$ ratio in the chest leads was normal but in 3 of these the $\mathrm{T}$ in V1, V2, V3 was negative or biphasic. Altogether such negative $\mathrm{T}$ waves were found in 18 cases and negative $\mathrm{T}$ waves in V1 and V2 in another 10.

Pagnoni and Goodwin (1952) accept $\mathrm{R}>\mathrm{S}$ in $\mathrm{V} 1$ and a ventricular activation time in $\mathrm{V} 1>$ $0.03 \mathrm{sec}$. as direct signs of R.V.H., and consider $\mathrm{S}>\mathrm{R}$ in V5 and a predominantly positive deflection in aVR as indirect signs indicative of extreme clockwise rotation or backward apical rotation, and virtually diagnostic of R.V.H. in the absence of cardiac infarction or right bundle branch block.

Indirect Signs. Our findings with regard to various indirect signs of R.V.H. have already been discussed and may be summarized by stating that right axis deviation $>100^{\circ}$, an algebraical sum of $\mathrm{R}+\mathrm{S}$ in lead $\mathrm{I}$ of $-3 \mathrm{~mm}$. or less, $\mathrm{S} / \mathrm{R}>1$ in V5, R/Q $>1$ in aVR, $\mathrm{S}$ in V5 $=5 \mathrm{~mm}$. or more and $\mathrm{R}$ in $\mathrm{aVR}=3 \mathrm{~mm}$. or more, all provide strong presumptive evidence for R.V.H. (Table I). Examples of complete regression of each sign are shown in Fig. 3.

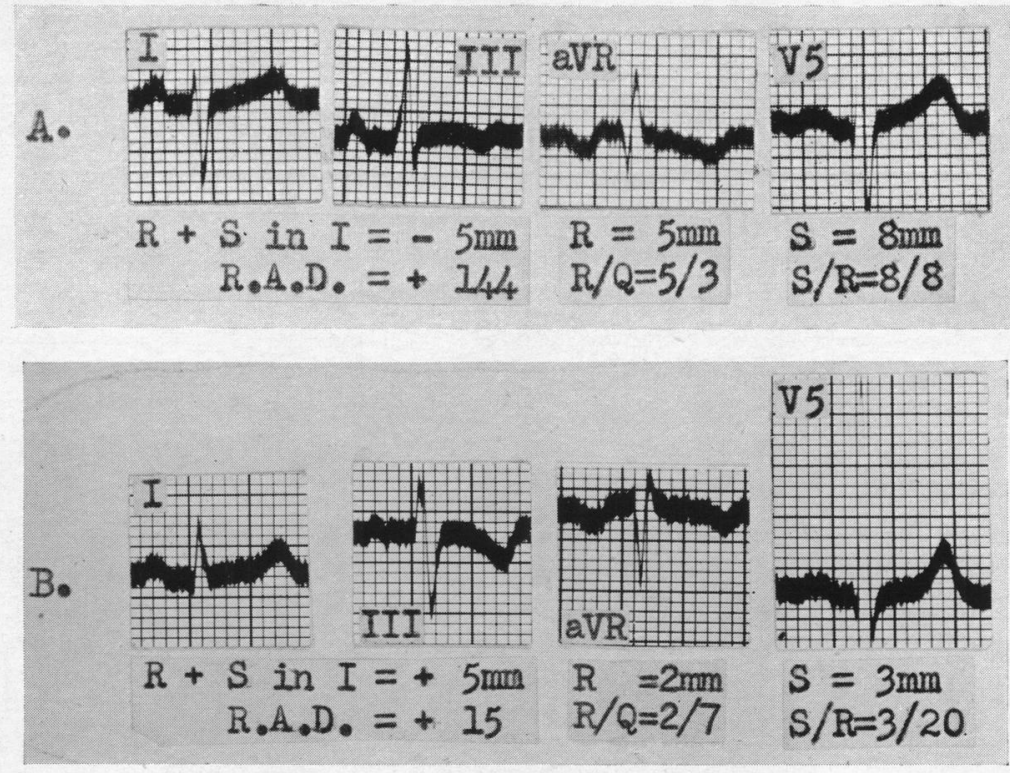

FiG. 3.-Regression of indirect signs of right ventricular hypertrophy following valvotomy. (A) Before operation. (B) After operation.

Direct Signs of R.V.H.

$R$ and $S$ in Pracordial Leads. The points studied were the height of $\mathrm{R}$, the depth of $\mathrm{S}$ and the $R / S$ ratio. First, it is appropriate to refer to the leads in which $R$ and $S$ measurements are usually made when seeking information about ventricular hypertrophy. It is customary to take V1 and V5. We consider it better to select for these measurements those leads in which the changes are maximal, provided of course that one can be certain over which ventricle the electrode has been placed. Not only does the degree of rotation of the heart about its longitudinal axis vary from patient to patient, but the electrodes are of considerable size and to some extent must overlap with regard to the changes of potential that they pick up. Chests vary considerably in shape and size. Breasts may present difficulty from size, mobility, and tissue resistance, and in practice technicians, who are usually responsible for recording the cardiograms, cannot be absolutely precise as to the positions where the electrodes are placed. Moreover, the thickness of the wall of the right ventricle is not uniform all the way round. In this series cardiographic changes of R.V.H. were found in $\mathrm{V} 1$ in 85 of the 115 cases $(74 \%)$. 
In our experience, changes attributable to R.V.H. may be more marked in V2 (and occasionally in V3) than in V1. One must, of course, be certain that V2 is being recorded over the right ventricle. In this series changes in V2 provided the sole evidence of R.V.H. in 4 cases and better evidence than V1 in 20 cases. The value of right-sided V leads (V3R, V4R, VE) is discussed below.

Similarly, changes directly attributable to L.V.H. and the depth of S indirectly suggesting R.V.H. may be more marked in V4 or V6 (recorded over the left ventricle) than in V5.

Most authors express their findings in tables which give maximum, minimum, and mean values for height of $\mathrm{R}$ and depth of $\mathrm{S}$.

TABLE II

Size of R and S Waves in 560 Healthy Adults (8 Authors*)

\begin{tabular}{|c|c|c|c|c|c|c|}
\hline & \multicolumn{3}{|c|}{$\mathbf{R}$} & \multicolumn{3}{|c|}{$\mathbf{S}$} \\
\hline & Min. & Max. & Mean & Min. & Max. & Mean \\
\hline $\begin{array}{l}\text { V1 } \\
\text { V2 } \\
\text { V5 } \\
\text { V6 }\end{array}$ & $\begin{array}{l}0 \\
0 \\
0 \cdot 4 \\
2 \cdot 0\end{array}$ & $\begin{array}{l}15.5 \\
23.0 \\
33.6 \\
22.6\end{array}$ & $\begin{array}{r}3 \cdot 1 \\
6.0 \\
12.0 \\
9.7\end{array}$ & $\begin{array}{l}0 \cdot 8 \\
0 \\
0 \\
0\end{array}$ & $\begin{array}{l}26 \cdot 2 \\
39 \cdot 2 \\
16 \cdot 1 \\
14.3\end{array}$ & $\begin{array}{r}9 \cdot 4 \\
14 \cdot 1 \\
2.0 \\
1.0\end{array}$ \\
\hline
\end{tabular}

* Taken from Nomenclature and Criteria for Diagnosis of Diseases of the Heart and Blood Vessels (1953), p. 178.

The number of cases in the upper, lower and intermediate ranges are rarely included. It is certain that maximum values in normals are far greater than the mean values in ventricular hypertrophy and that the electrocardiographic diagnosis of ventricular hypertrophy would rarely indeed be made if only values above the upper range of normal were accepted. It must, therefore, be concluded that absolute criteria of practical value for the electrocardiographic diagnosis of ventricular hypertrophy are impossible to deduce from most published tables. Tables that give the scatter in the various ranges are more useful but even then conclusions as to presumptive evidence for ventricular hypertrophy on electrocardiographic grounds can only be based on high probability. Nevertheless, in practice, presumptive evidence for ventricular hypertrophy on one criterion may be provided and serve as a useful stimulus to look with particular care for other cardiographic evidence and may materially influence the overall assessment of the patient.

\section{Right Ventricular Leads}

In right ventricular hypertrophy (R.V.H.) the $\mathrm{R}$ waves in leads recorded over the right ventricle are characteristically tall and the $S$ is small. All authors refer to the $R / S$ ratio in V1 but only Sokolow and Lyon (1949) consider the absolute height of $\mathrm{R}$ and they do not refer to the diagnostic significance of a tall $\mathrm{R}$ in cases in which the $\mathrm{R} / \mathrm{S}$ ratio $<1$. Most authors only refer to lead V1.

$R / S$ Ratio. As mentioned above $\mathrm{R} / \mathrm{S}>1$ in $\mathrm{RV}$ leads is generally accepted as a sign of R.V.H. In normal adults Leatham (1950) found $\mathrm{R} / \mathrm{S}$ in V1 was always $<1$ and the maximum ratio recorded by Sokolow and Friedlander (1949) was 1 . In our consecutive series of 2000 cardiograms $R / S>1$ was not found in any patient without some pathological condition likely to give rise to R.V.H. In the post-mortem series all 14 cases with $R / S>1$ had anatomical R.V.H. In the operation series $R / S$ in V1 was $>1$ in 61 cases and in V2 (recorded over the right ventricle) in an additional 3, all of whom had strong presumptive evidence for R.V.H. on other grounds; we have never found R/S $>1$ in a patient with mitral stenosis in the absence of such presumptive evidence. In 16 (additional) cases this criterion was only present in V3R, V4R, or VE. It may be worth emphasizing that even if the absolute height of $R$ is small, $R / S>1$ signifies R.V.H. (Fig. 4). In the operation series there were 22 such cases in which $R$ was $<5 \mathrm{~mm}$. and this included 12 with $R=4,6$ with $R=3$, and 4 with $R=2$. Our experience therefore confirms the value of the $R / S$ ratio. It is noteworthy that of 


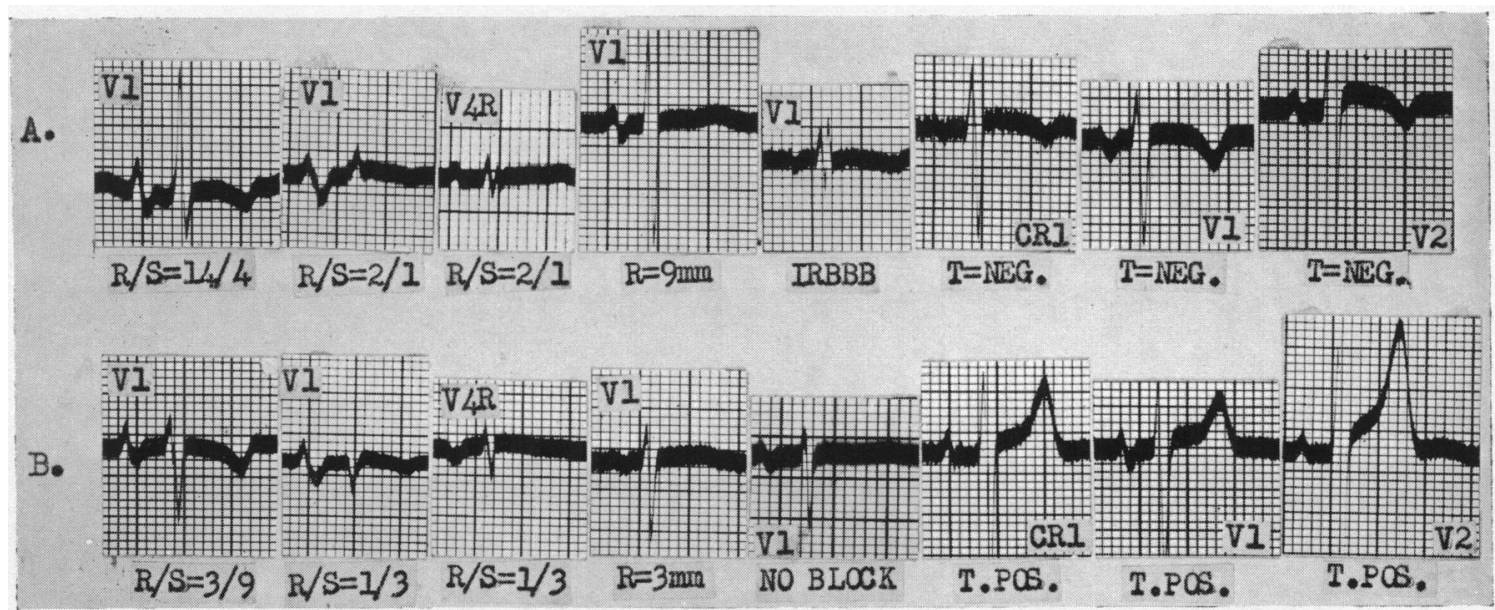

FIG. 4.-Regression of patterns of right ventricular hypertrophy following valvotomy. (A) Before operation. (B) After operation.

115 cases in which an electrocardiographic diagnosis of R.V.H. was made on the criteria recommended in this paper, the $\mathrm{R} / \mathrm{S}$ ratio was $<1$ in $33(29 \%)$.

Absolute Height of $R$. Leatham (1950) found the upper limit of normal for R waves in V1 was $8 \mathrm{~mm}$. and Sokolow and Friedlander (1949) $7 \mathrm{~mm}$. but Graybiel et al. (1952) state that R may be $10 \mathrm{~mm}$. high in health. Table II gives a maximum value for R in V1 of $15.5 \mathrm{~mm}$. This far exceeds the mean and maximal values quoted by most authors. We have studied the source from which this table was compiled and it appears that this maximal figure refers to an exceptional single case quoted by one author.

In the 64 cases in the operation series in whom $R / S>1$ in V1(2), $R$ was more than $10 \mathrm{~mm}$. in 13 and $7-10 \mathrm{~mm}$. in 15 . It is noteworthy that in the 115 cases in which an electrocardiographic diagnosis of R.V.H. was made the absolute height of $R$ was $4 \mathrm{~mm}$. or less in $58(49 \%)$.

Sometimes the $\mathbf{R}$ and $\mathbf{S}$ waves are both of exceptionally high voltage. Since in R.V.H. the $\mathrm{S}$ wave in V1(2) is characteristically small or absent, when a deep S (as in Fig. 5) accompanies a tall $\mathrm{R}$, we felt reluctant at first in accepting its significance as a sign of R.V.H. but we have observed regression after operation, and in the post-mortem series all cases (11) with $R>7$, irrespective of the R/S ratio, had marked anatomical R.V.H. (Fig. 6).

In the operation series there were 10 patients in whom $R>7 \mathrm{~mm}$. in V1 was associated with a deep $\mathrm{S}$ so that the $\mathrm{R} / \mathrm{S}$ ratio $<1$. It is noteworthy that not only was there a deep $\mathrm{S}$ wave in $\mathrm{V} 1$ but that the clockwise rotation so commonly present in patients with R.V.H., as judged by an $\mathrm{S}$ wave over the left ventricle, was absent in all but one of these cases. This suggests that the pattern is influenced by the electrical position of the heart. However, it does not influence our conclusion from all the evidence quoted above that an absolute height of $R>10 \mathrm{~mm}$. in leads recorded over the right ventricle almost certainly indicates the presence of R.V.H. and one $>7 \mathrm{~mm}$. is strongly suggestive.

Left Ventricular Leads. In R.V.H. the S waves in leads recorded over the left ventricle tend to be deeper and to present further to the left than in normal hearts, i.e. as far round as V5, V6, or V7. How far to the left the $\mathrm{S}$ is recorded is a measure of clockwise rotation and hence indirectly often a sign of R.V.H. as already discussed.

In our series the mean depth of S in V5 was $4.1 \mathrm{~mm}$. (0-33) and in V6 $1.8 \mathrm{~mm} .(0-20)$ for those with R.V.H., and for those without R.V.H. $1 \cdot 1 \mathrm{~mm} .(0-10)$ in V5, and $0 \cdot 1 \mathrm{~mm} .(0-3)$ in V6 respectively. 


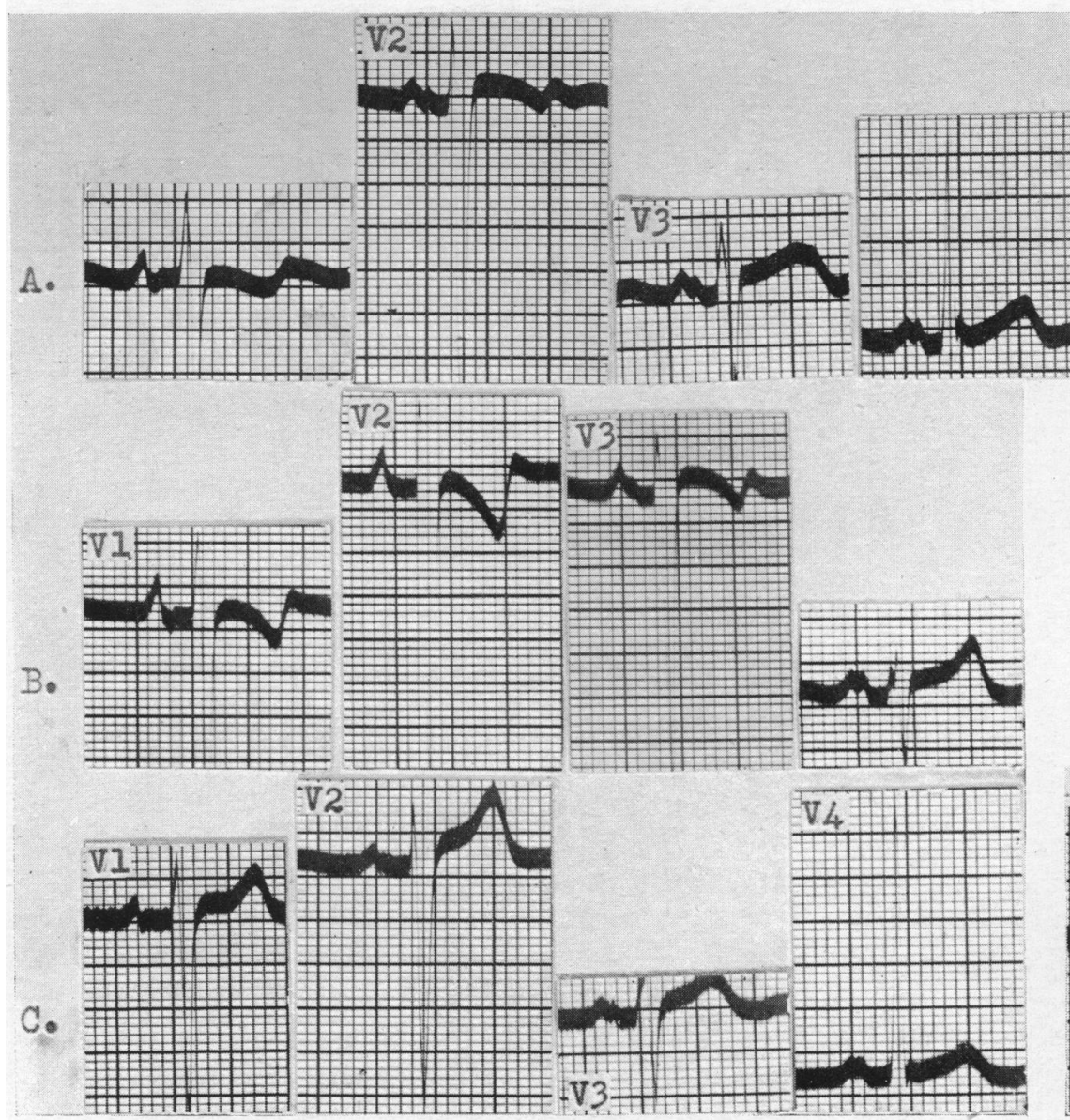

FIG. 5

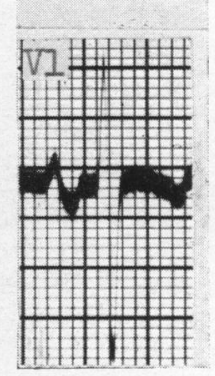

Fig. 6

FIG. 5.-Progression of right ventricular hypertrophy before operation and regression afterwards. (A) 29/3/50, before operation. (B) $14 / 3 / 51$, before operation. (C) $31 / 7 / 51$, after operation.

FIG. 6. - Right ventricular hypertrophy. Tall $R$ and deep $S$ in $V 1$. $R / S=12 / 16 \mathrm{~mm}$. Post-mortem contro confirmed R.V.H.

Sokolow and Lyon (1949) state that R.V.H. may be suspected when S $>$ R in V5, and also consider that certain combined measurements are of value in this respect, i.e. $\mathrm{R}$ in $\mathrm{V} 1+\mathrm{S}$ in $\mathrm{V} 5>$ $10.5 \mathrm{~mm}$. and the ratio of $\mathrm{R} / \mathrm{S}$ in V5 divided by $\mathrm{R} / \mathrm{S}$ in $\mathrm{V} 1<0.4$. Pagnoni and Goodwin (1952) also consider that $S>R$ in V5 is a valuable indirect sign of R.V.H. These criteria have been considered in all our cases but in no instances do they give positive information in the absence of other electrocardiographic signs of R.V.H.

Right-Sided $V$ Leads. When the conventional præcordial leads do not provide evidence of R.V.H. or the signs are equivocal, it is worth while recording leads from other positions on the chest wall (Fig. 7). We have studied the value of V3R, V4R, and VE. V3R and V4R are recorded to the right of the sternum in the intercostal positions corresponding to V3 and V4 on the left. VE is recorded over the ensiform cartilage (Fig. 8). Myers et al. (1948) noted that V3R alone gave positive cardiographic evidence of R.V.H. in 2 out of 40 autopsy cases, and Barker and Valencia (1949) showed that V3R, V4R, and VE were sometimes of decisive importance in the detection of incomplete right bundle branch block. 

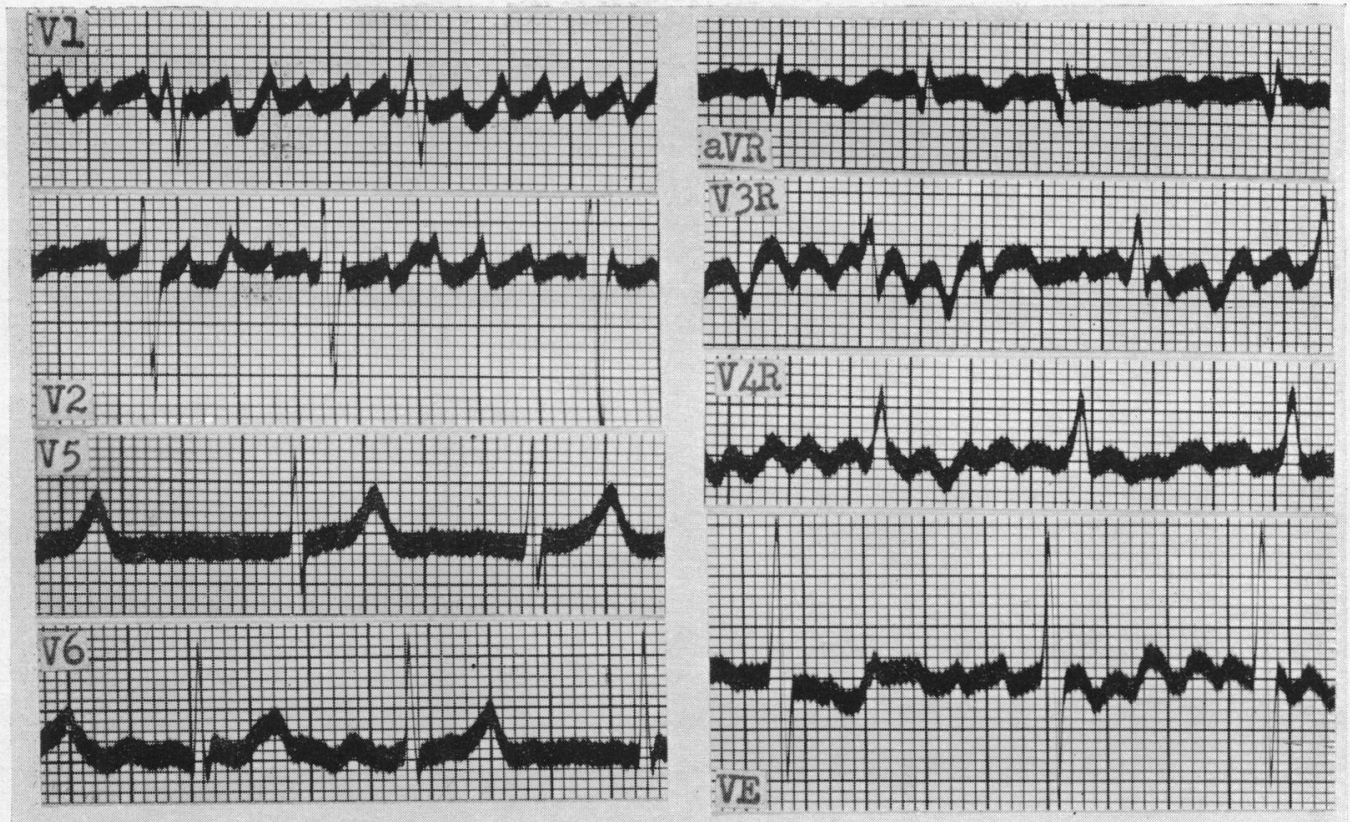

FIG. 7.-Right ventricular hypertrophy. To illustrate the value of right-sided V leads. The only possible indication of R.V.H. in the conventional leads is a slight degree of incomplete right bundle branch block in V2. V4R is diagnostic of R.V.H.

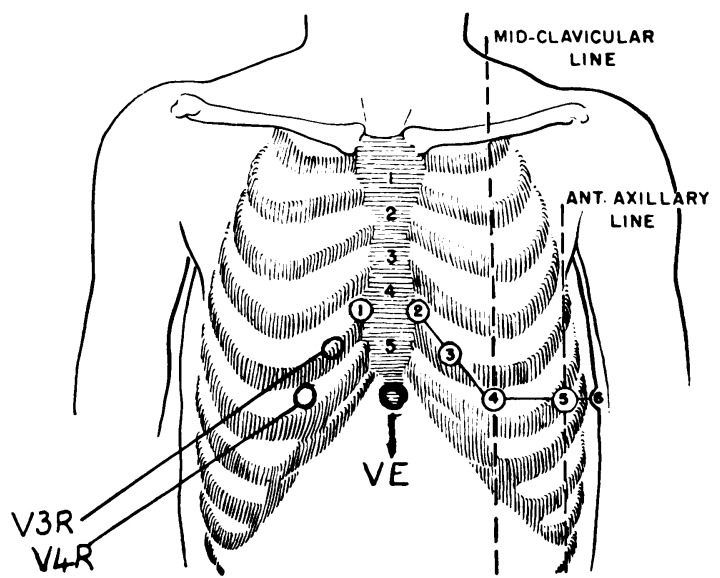

FIG. 8.-The electrocardiographic diagnosis of R.V.H. was made in 115 of the 177 cases of mitral stenosis $(65 \%)$. Right-sided V leads were recorded in 95 of these $115(83 \%)$ and were positive in 76 of the 95 $(80 \%)$. V4R was positive in 73 of the 76 in which it was recorded $(96 \%)$. Right-sided V leads were positive and the sole sign of R.V.H. in 16 of the $95(17 \%)$.

V3R, V4R, and VE were recorded pre-operatively in 141 patients in our series and in 95 of the 115 cases in which a cardiographic diagnosis of R.V.H. was made. In 76 of the 95 the R/S ratio $>1$ in one or more of these leads. All had strong presumptive evidence of R.V.H. on grounds other than electrocardiographic. $R / S>1$ has never been seen in the absence of such evidence. In the post-mortem series, anatomical evidence of R.V.H. was present in each of the 11 cases in which this 
ratio had exceeded unity. Accordingly an $\mathrm{R} / \mathrm{S}>1$ in V3R, V4R, or VE has been accepted as a positive criterion for R.V.H. In 16 of the 115 cases, positive findings in these leads were the sole electrocardiographic sign (Fig. 9). The right-sided V leads more frequently gave evidence of R.V.H. than any other leads but in 11 cases where the usual præcordial leads provided evidence of R.V.H. this was lacking in the right-sided leads.

It is concluded that when R.V.H. is suspected on clinical grounds but not revealed in the customary pracordial leads, significant changes may be found in V3R,V4R, or VE in 15-20 per cent of the cases; but that from the practical point of view, since V4R was positive in 96 per cent of the cases in which right-sided V leads gave evidence of R.V.H., it will usually be sufficient to record V4R.

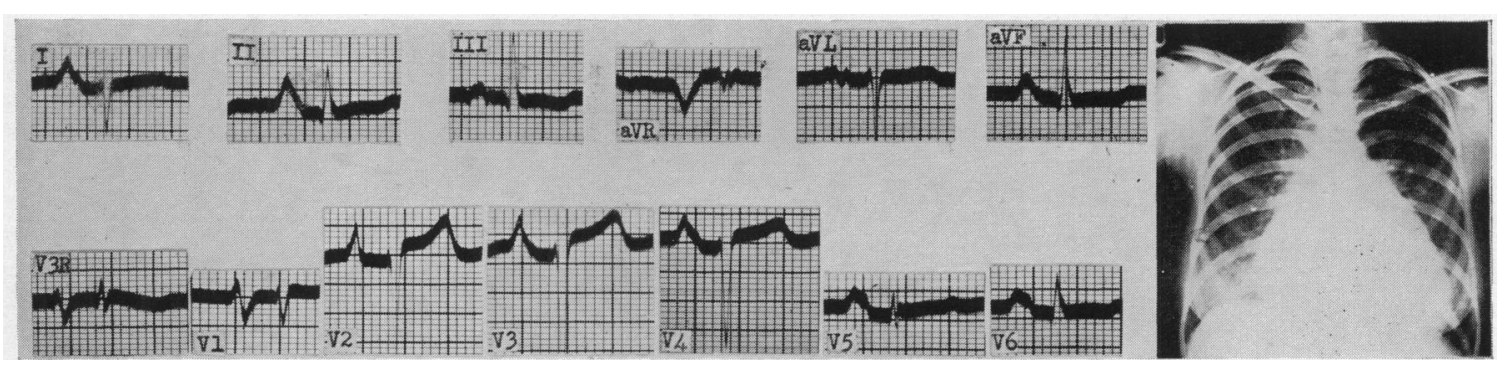

Fig. 9.-Considerable cardiac enlargement (cardio-thoracic ratio $62 \%$ ). Sole sign of right ventricular hypertrophy in V3R. Tight mitral stenosis.

It is of interest that an electrode placed in the fifth right intercostal space in the mid-clavicular line should serve so well in providing evidence for R.V.H. This emphasizes the present lack of knowledge of the precise mechanism of the genesis of electrocardiographic signs of R.V.H. Goldberger (1945), Kossman et al. (1948), and McGregor (1950) discuss this problem and the last author suggests that the electrocardiographic pattern of R.V.H. may be due to pronounced rotation of the heart with almost complete reversal of the electrical fields of the two ventricles in the thorax. In many of our cases, however, there was no other evidence to suggest that such a large degree of rotation was present and it is uncommon for the surgeon undertaking valvotomy to detect such a conspicuous change of position, e.g. with reference to the position of the descending branch of the left coronary artery.

$Q$ Waves. Myers et al. (1948) state that a Q in V1 is common in R.V.H. but Donzelot et al. (1951) found it in only 70 per cent and Woods (1952) in 15 per cent of cases of Fallot's tetralogy. In our series a $\mathrm{Q}$ in V1 occurred in 19 cases all of which had other cardiographic signs of R.V.H., i.e. it occurred in 19 out of 177 cases $(11 \%)$ of mitral stenosis and in 19 out of $95(20 \%)$ of those in whom an electrocardiographic diagnosis of R.V.H. was made. In an additional 10 cases a $Q$ wave was present only in V3R or V4R. Four of the post-mortem cases showed a Q in V1 and the relation between this and the thickness of the right ventricular wall was as below.

$$
\begin{array}{lcllc}
\text { R/S in V1 } & 8 / 0 & 3 / 1 & 8 / 0 & 11 / 0 \\
\text { R.V. thickness (mm.) } & 9 & 11 & 12 & 9
\end{array}
$$

Each case had strong presumptive evidence for R.V.H. but in the series as a whole there was no close correlation between this and the presence or absence of $Q$ waves.

\section{Right Bundle Branch Block}

Right bundle branch block (R.B.B.Bl.) is usually diagnosed when leads over the right ventricle show primary $(R)$ and secondary $\left(R^{\prime}\right)$ waves separated by a downward deflection, when there is no $Q$ wave, and when the ventricular activation time (V.A.T.) is prolonged. Most authors differentiate complete from 
incomplete block according to whether QRS is $\mathbf{0 . 1 2}$ of a second or more or less than this in duration. However, incomplete block is a matter of degree and merits further discussion. Polyphasic complexes are common but there are no agreed criteria as to what constitutes incomplete block nor as to the significance that can be attached to this finding. A wide variety of polyphasic complexes may be seen and not always is the total duration of QRS or the V.A.T. prolonged. Tall initial or secondary upward deflections are usually designated as $\mathbf{R}$ and $\mathbf{R}^{\prime}$ respectively and similar but small complexes as $\mathbf{r}$ and $\mathbf{r}^{\prime}$. Carouso et al. (1951) state that complexes that include a tall $\mathrm{R}$ suggest R.V.H. but that patterns of types $\mathrm{rSr}^{\prime}, \mathrm{rsr}^{\prime}, \mathrm{rsr}^{\prime} \mathrm{s}^{\prime}$ and $M$ cannot be accepted as evidence of this. In one of the tables in their paper it is clear that the designation of $R$ was given to a wave of $2 \mathrm{~mm}$. amplitude and presumably all $R$ waves $>2 \mathrm{~mm}$. are to be designated likewise. We have been unable to find any reference to absolute measurement for deciding whether an R or $r$ wave is " tall " or " short ". According to Barker and Valencia (1949) R.V.H. associated with incomplete R.B.B.Bl. (I.R.B.B.Bl.) can be diagnosed when the secondary $R$ wave $\left(R^{\prime}\right)$ is $>10 \mathrm{~mm}$. in height. Carouso et al. show that this criterion is too severe because R.V.H. was found anatomically in 21 of 24 cases with I.R.B.B.Bl. that would not have been classified on these electrocardiographic grounds as

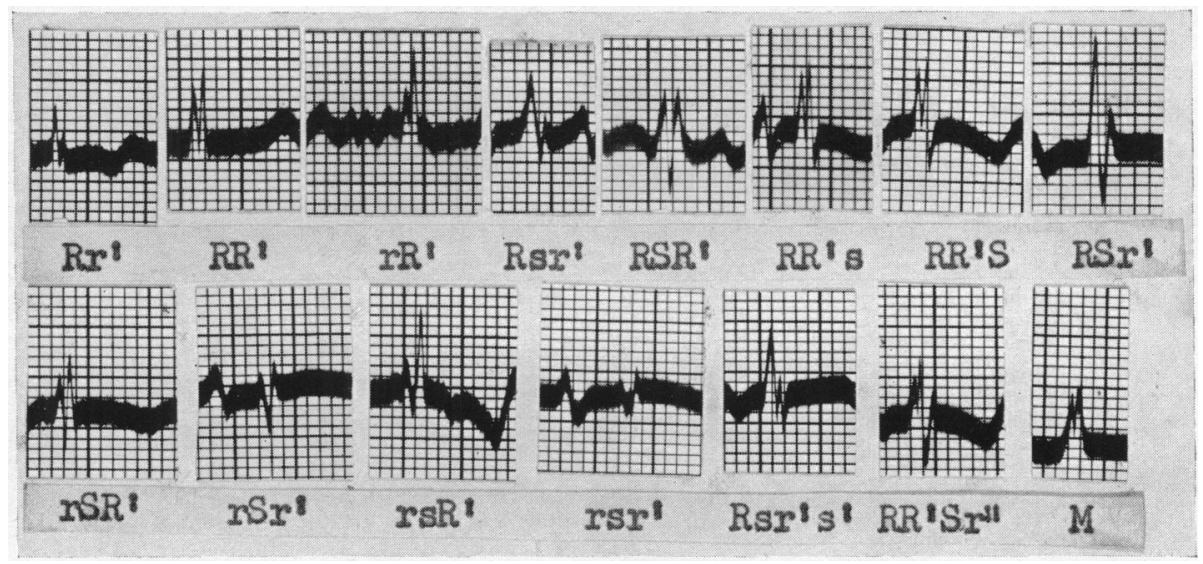

FIG. 10.-Patterns of incomplete right bundle branch block (Lead V1).

having R.V.H. Myers et al. (1948) state that in the chest leads of patients with I.R.B.B.Bl., QRS $<0 \cdot 12$ sec. and V.A.T. $=0.05$ to $0.075 \mathrm{sec}$. Wilson (1947) states that the QRS is 0.09 to 0.11 and Carouso et al. state that QRS $<0.11$ and V.A.T. is prolonged.

In some subjects the QRS is normally less than the more usual $0.08 \mathrm{sec}$. in chest leads. If bundle branch conduction is impaired in such an individual it is clear that a normal of $0.08 \mathrm{sec}$. would in fact represent delayed conduction although by customary definition this would not be accepted as a case of bundle branch block.

Occasionally I.R.B.B.Bl. has been reported in perfectly normal persons. Pathologically it occurs most commonly in rheumatic, ischæmic, and congenital heart disease and may be seen transiently in acute cardiac dilatation. We have not recorded a full series of cardiograms in a sufficiently large number of normal subjects but believe that polyphasic complexes must at least be very uncommon in health. We have analysed the cardiograms in 2000 consecutive cases and polyphasic complexes over the right ventricle with QRS $<0.12 \mathrm{sec}$. were found in 60 instances as follows, but never in the absence of one of these conditions: ischæmic heart disease (16 cases), cor pulmonale (13), atrial septal defect (6), ventricular septal defect (5), constrictive pericarditis ( 8$)$, and mitral stenosis (12 cases).

In this series of 200 cases with mitral stenosis subjected to valvotomy complete R.B.B.Bl. were recorded in one case and polyphasic complexes QRS $<0.12 \mathrm{sec}$. (I.R.B.B.Bl.) in 45 cases. In 10 V.A.T. was $<0.05 \mathrm{sec}$. and in 35 it was $0.05 \mathrm{sec}$. or more in duration. A considerable variety of patterns occurred and included the following: $\mathrm{Rr}^{\prime}, \mathrm{RR}^{\prime}, \mathrm{rR}^{\prime}, \mathrm{Rsr}^{\prime}, \mathrm{RSr}^{\prime}, \mathrm{RSR}^{\prime}, \mathrm{RsR}^{\prime}, \mathrm{RR}^{\prime} \mathrm{s}, \mathrm{rSR}^{\prime}, \mathrm{rSr}^{\prime}, \mathrm{rsR}^{\prime}, \mathrm{rsr}^{\prime}, \mathrm{RR}^{\prime} \mathrm{sr}^{\prime \prime}$, $\mathrm{Rsr}^{\prime} \mathrm{s}^{\prime}$ and $\mathrm{M}$ (Fig. 10). Difficulties may sometimes arise in cases with auricular fibrillation in which $f$ waves are superimposed on the QRS complex. In cases of doubt close inspection of all the complexes in V1 and if necessary the recording of lead CR1 will serve to distinguish the two patterns (Fig. 11). 


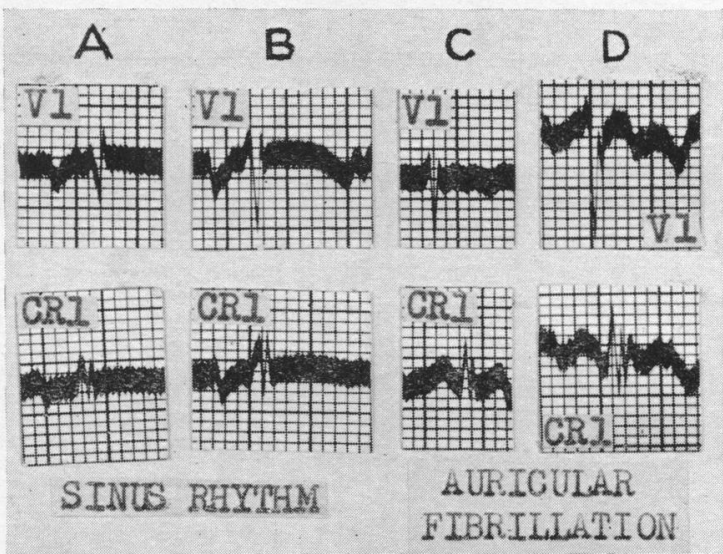

FIG. 11.-CR1 confirming doubtful pattern of incomplete right bundle branch block in V1. (A)-(D) are from four different cases.

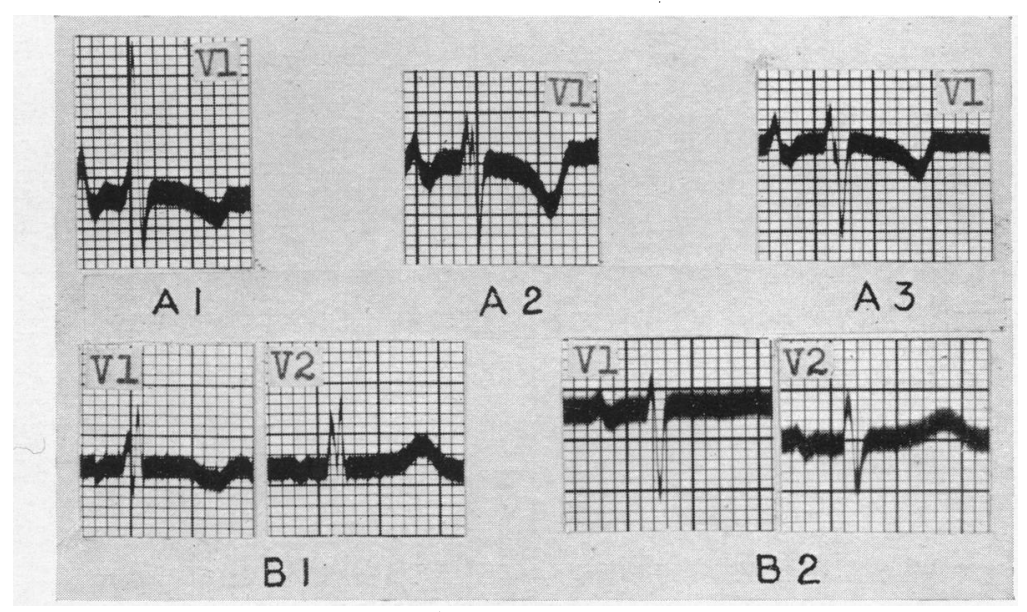

Fig. 12.-(A) Development and regression of incomplete right bundle branch block; (A1) before operation, (A2) 6 months after operation, and (A3) 12 months after. (B) Regression of incomplete right bundle branch block; (B1) before operation, and (B2) 18 months after.

In the post-mortem series, there were 11 examples of I.R.B.B.Bl. and anatomically all had definite R.V.H. Moreover, in the operation series of 200 patients and in a parallel series of 200 patients not subjected to operation we have never seen I.R.B.B.Bl. in the absence of strong presumptive evidence for R.V.H. on clinical and radiological grounds. After operation the pattern may regress (Fig. 12).

Further support for this criterion is given by the examples shown in Fig. 13, in which it will be seen that the pattern of I.R.B.B.Bl. in V1 is accompanied by a strongly positive R/S ratio in CR1 or in V4R or VE.

For all these reasons it is concluded that although in patients with mitral stenosis the pattern of I.R.B.B.Bl. cannot be accepted as definite direct evidence, because it is possible that it may be due to a defect of conduction from rheumatic myocarditls or ischamia, from the practical point of view it is unlikely to be found except in the presence of R.V.H. 


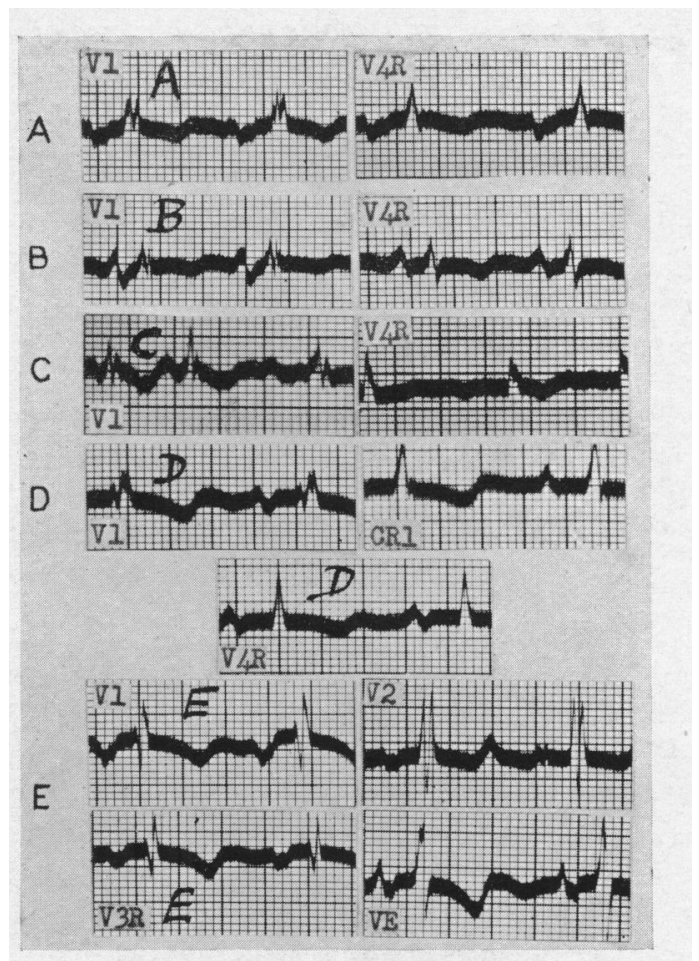

FIG. 13.-Electrocardiographic diagnosis of right ventricular hypertrophy. Illustrating the value of right-sided V leads (V3R, V4R, VE). The pattern of incomplete right bundle branch block in $\mathrm{V} 1$ is associated with a strongly positive $R / S$ ratio in the right sided $\mathrm{V}$ leads.

\section{Negative T Waves}

Negative $\mathrm{T}$ waves in leads recorded over the right ventricle commonly accompany other electrocardiographic signs of R.V.H. Myers et al. (1948) state that a negative T in V1 cannot by itself be attributed to R.V.H. unless characteristic changes in the QRS complex are also present. Our experience confirms that of Leatham (1950) and of Myers et al. (1948) that occasionally the T wave in V1 may be negative in health although under these circumstances it is never, after childhood, more than $2.5 \mathrm{~mm}$. in depth.

Out of this series of 200 patients subjected to operation in whom there was no other cardiographic evidence of R.V.H. but presumptive evidence for such hypertrophy on other grounds, a negative $\mathrm{T}$ in $\mathrm{V} 1$ was accompanied by a negative $\mathrm{T}$ in $\mathrm{V} 2$ in 5 patients and by a negative $\mathrm{T}$ in $\mathrm{V} 2$ and $V 3$ in 2 patients, by a negative $T$ wave in CR 1 in 7 cases and in both CR1 and V2 in 5 patients. The 7 patients in whom $\mathrm{T}$ was negative in CR1 and V1 have not been included in the number of positive cases because we consider the evidence suggestive rather than conclusive.

It is appreciated that similar $\mathrm{T}$ wave inversions may occur in so-called right ventricular strain, e.g. acute cor pulmonale. The term right ventricular "strain" commonly applied to such negative $\mathrm{T}$ waves is not satisfactory because "strain" has no precise connotation. It might presumably arise from dilatation, anoxia, ischæmia, or from biochemical changes. In the patients under consideration no acute episodes had occurred and in all except one the changes were persistent and sometimes progressive. In one patient the changes receded during a period of rest in hospital. Following valvotomy these signs sometimes regress (Fig. 5). 
It is concluded that in patients with mitral stenosis in the absence of any other obvious cause such as acute cor pulmonale, pericarditis, or myocardial infarction, a negative $T$ wave in VI if accompanied by a negative $T$ in $V 2$ can be taken as presumptive, and in CR1 as suggestive, evidence of R.V.H.

\section{MYOCARDitis PATtern}

It is difficult to prove that an electrocardiographic pattern can be attributed to fibrotic changes resulting from rheumatic myocarditis. We have suspected an abnormal $T$ wave pattern in 4 cases (Fig. 14) in the absence of any other obvious cause, the persistence of the pattern after a successful

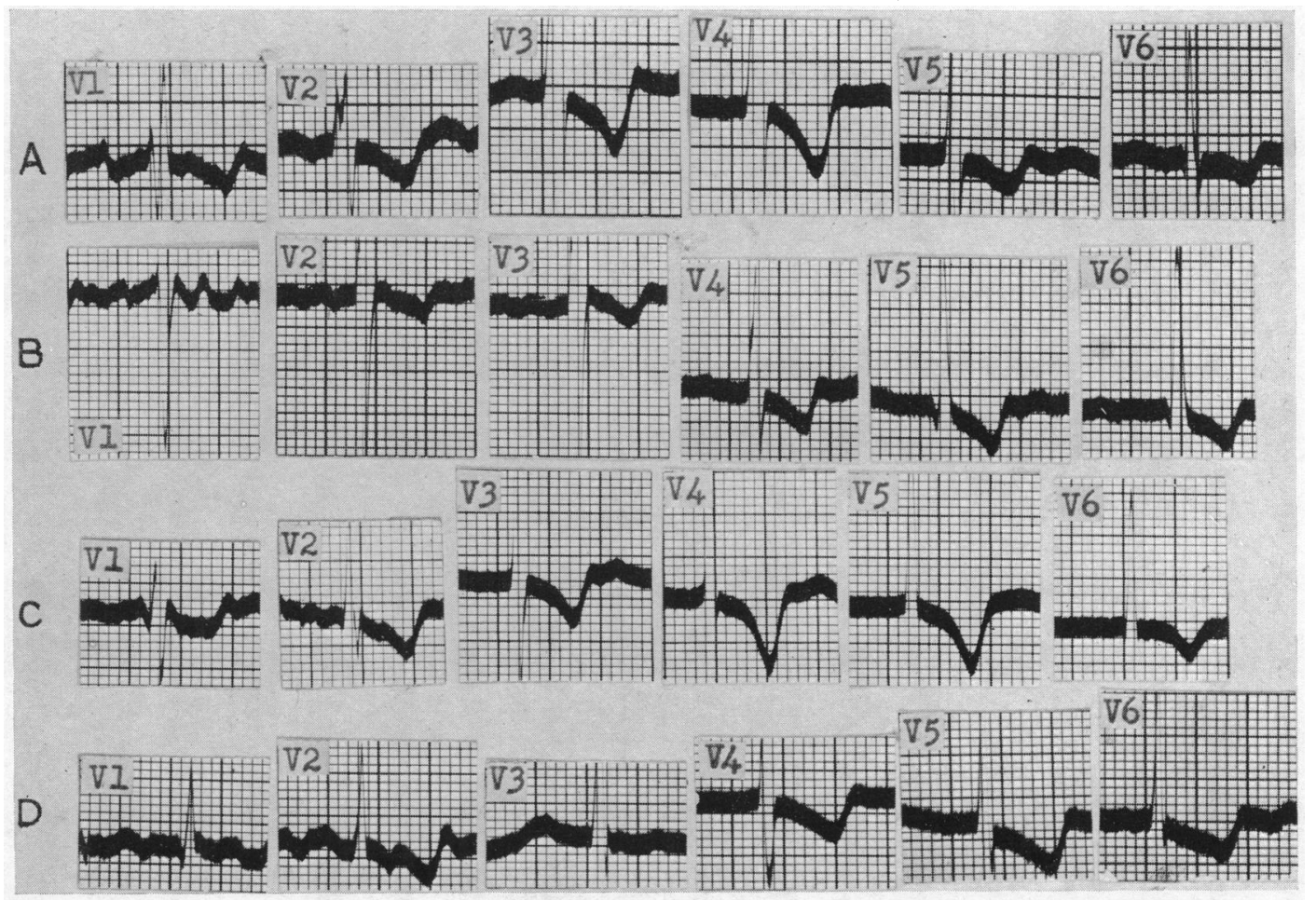

Fig. 14.-Negative $T$ waves. ? Fibrosis pattern.

valvotomy, and in one case by correlation with post-mortem findings. The pattern is similar in the 4 cases and not characteristic of ventricular hypertrophy or that usually resulting from digitalis. Case 6 was the only one on digitalis. No cause for L.V.H. was present in any of them.

This pattern is uncommon in spite of the presumed frequency of rheumatic myocarditis, and in 7 cases we have studied in which microscopical changes attributable to old rheumatic myocarditis were reported by the pathologist, no suggestive cardiographic changes were recorded.

\section{Ventricular Activation Time}

The time interval measured from the commencement of the $Q$ wave to the peak of $R$ (or in cases where there is no $Q$ wave, from the beginning of $R$ to the peak of $R$ ) is termed the "ventricular activation time" (V.A.T.) and is commonly considered to be an expression of the thickness of the ventricular wall underlying the electrode.

In lead V1 (or V2) over the right ventricle, the V.A.T. is normally <0.03 sec. (Myers et al., 1947; Sokolow and Friedlander, 1949; Carouso et al., 1951; Kossman, 1953) and an increase in this time above the normal 
is taken to indicate R.V.H. (Myers et al., 1948; Sokolow and Lyon, 1949). The V.A.T. has been measured in all cases in this series but in the 115 cases with electrocardiographic evidence of R.V.H., a V.A.T. $>0 \cdot 03$ sec. was found in only 62 . In 45 of them, this was associated with polyphasic QRS complexes. In no case was the V.A.T. abnormal in the absence of other electrocardiographic signs of R.V.H. Presumably this is due to the fact that in spite of considerable R.V.H. the width of the free wall of the left ventricle is still greater than that of the right ventricle and hence tends to neutralize the potential electrocardiographic signs of R.V.H. The V.A.T. was often normal in cases with clear-cut cardiographic signs of R.V.H. on other grounds.

Myers et al. (1948) suggest that V.A.T. in V1 which is greater than that in V5 or V6 indicates R.V.H. In our series when V.A.T. in V1 was 0.05 sec. or greater, it always exceeded that in V5, but in 3 cases where V.A.T. in V1 was $0.04 \mathrm{sec}$., it did not exceed that in V5 although R.V.H. was definitely present on other cardiographic grounds. It is, therefore, concluded that as a sign of R.V.H. an increased V.A.T. in V1 need not, in addition, be greater than that in V5. Two of these three showed V.A.T. in V1 the same as that in V5 $(0.04 \mathrm{sec}$.) and in the third case, which had complete R.B.B.Bl., it was $0.05 \mathrm{sec}$. in V5. Woods (1952) in cases of tetralogy of Fallot found that in 96 per cent V.A.T. in V6 was either less than (94\%) or equal to (2\%) V.A.T. in V1. This emphasizes the difference between the incidence of prolongation of V.A.T. in V1 in congenital pulmonary stenosis and that in mitral stenosis. In most of the papers in which reference to the V.A.T. is made, R.V.H. due to congenital heart disease, cor pulmonale, and mitral valvular disease have been grouped together.

It is concluded that in patients with mitral stenosis, the degree of R.V.H. is relatively less than that which occurs in, e.g. congenital heart disease or cor pulmonale, and that this measurement is of little practical value.

\section{Depression of THE S-T SEgment}

Depression of the S-T segment below the iso-electric line in leads recorded over the right ventricle may be found in association with other electrocardiographic signs of R.V.H. and occurred in 13 patients of this series. No significance to this finding per se can be paid in those taking digitalis. Transient depression from ischæmia is discussed below. In patients with R.V.H. from congenital heart disease, particularly in pulmonary stenosis with an intact ventricular septum, tall $\mathrm{R}$ and negative $\mathrm{T}$ waves are commonly associated with S-T depression and it might be thought that $\mathrm{S}-\mathrm{T}$ depression was a measure of severity. In this series of patients with mitral stenosis, S-T depression $>0.5 \mathrm{~mm}$. was recorded in only 13 cases, in 9 of whom the $R$ wave was $>7 \mathrm{~mm}$. and in 4 of these was $R>10 \mathrm{~mm}$. None was taking digitalis. All these cases had severe mitral stenosis with considerable pulmonary hypertension, all had cardiographic signs of R.V.H., and the pattern was well developed in 11. One case came to necropsy; the thickness of the right ventricle was $9 \mathrm{~mm}$. and the left ventricle was $12 \mathrm{~mm}$., and the heart weight was $560 \mathrm{~g}$.

It is concluded that $S-T$ depression from right ventricular hypertrophy occurs only when the latter is gross, but since it is absent in many cases known to have considerable hypertrophy, it is an unimportant sign in patients with mitral stenosis.

\section{GRADING OF R.V.H.}

After analysing the electrocardiographic changes in each case we attempted to grade the degree of severity of R.V.H. but found the task impossible. In the first place one cannot be sure of the relative importance of the various criteria for R.V.H.

It would seem reasonable to assume that the taller the $R$ and the greater the $R / S$ ratio over the right ventricle, the greater the degree of R.V.H. but certainly the converse does not hold. In the operation series there was a wide discrepancy between cardiographic signs of R.V.H. and presumptive evidence for it on other grounds. In the post-mortem series there were 18 patients in which the thickness of the right ventricular wall was 8-12 mm. and in this group the height of $R$ varied indiscriminately between $1-15 \mathrm{~mm}$. and the $\mathrm{R} / \mathrm{S}$ ratio from $0 \cdot 1$ to $11 \cdot 0$.

The detailed findings in all our post-mortem cases with adequate cardiographic and autopsy measurements are shown in Table III. The lack of correlation between electrocardiographic signs of R.V.H. and the presence of anatomical R.V.H. is striking, and in particular the correlation between the better developed cardiographic signs of R.V.H. and the more pronounced degrees of anatomical R.V.H. is seen to be poor.

Similar findings in relation to cases of the tetralogy of Fallot with post-mortem studies have been noted 
by Donzelot et al. (1951) (10 cases), and Woods (1952) (7 cases). Pagnoni and Goodwin (1952) also comment on this disparity in their series of cases with biventricular hypertrophy.

It is probable that in the pattern commonly taken to indicate incomplete right bundle branch block the absolute height of $R$ and the $R / S$ ratio have the same significance as when block is not present.

TABLE III

Correlation of Right Ventricular Hypertrophy and R/S in Vi after Necropsies (36)

\begin{tabular}{|c|c|c|c|c|}
\hline \multirow{2}{*}{ Case No. } & \multirow{2}{*}{$\begin{array}{l}\text { Heart weight } \\
\text { (g.) }\end{array}$} & \multicolumn{2}{|c|}{ Thickness (mm.) of } & \multirow{2}{*}{$\begin{array}{l}\mathrm{R} / \mathrm{S} \\
\text { in } \mathrm{V} 1\end{array}$} \\
\hline & & R.V. & L.V. & \\
\hline $\begin{array}{r}3 \\
35 \\
38 \\
43 \\
52 \\
57 \\
79 \\
87 \\
91 \\
96 \\
99 \\
107 \\
114 \\
116 \\
145 \\
147 \\
162 \\
168 \\
170 \\
185 \\
186 \\
187 \\
188 \\
196\end{array}$ & $\begin{array}{l}650 \\
560 \\
600 \\
340 \\
320 \\
500 \\
560 \\
400 \\
650 \\
490 \\
380 \\
650 \\
610 \\
500 \\
500 \\
680 \\
580 \\
600 \\
460 \\
440 \\
560 \\
660 \\
480 \\
770\end{array}$ & $\begin{array}{c}+ \\
5 \\
12 \\
8 \cdot 5 \\
6 \\
13 \\
9 \\
+ \\
8 \\
11 \\
5 \\
15 \\
8 \\
12 \\
9 \cdot 5 \\
11 \\
12 \\
7 \\
7 \\
10 \\
5 \cdot 5 \\
5 \\
12 \\
9\end{array}$ & $\begin{array}{l}+ \\
13 \\
14 \\
15 \\
10 \\
15 \\
12 \\
+ \\
12 \\
12 \\
15 \\
30 \\
20 \\
21 \\
11 \\
10 \\
13 \\
15 \\
16 \\
15 \\
13 \\
13 \\
16 \\
13\end{array}$ & $\begin{array}{c}0 / 6 \\
1 / 13 \\
6 / 1 \\
3 / 0 \\
12 / 16 \\
8 / 2 \\
8 / 0 \\
7 / 15 \\
1 / 6 \\
3 / 1 \\
1 / 8 \\
8 / 31 \\
0 / 4 \\
2 / 5 \\
0 / 11 \\
3 / 1 \\
15 / 1 \\
1 / 14 \\
6 / 12 \\
7 / 1 \\
0 / 9 \\
2 / 5 \\
8 / 1 \\
11 / 0\end{array}$ \\
\hline $\begin{array}{l}\text { A } \\
\text { B } \\
\mathbf{C} \\
\mathbf{E} \\
\mathbf{F} \\
\mathbf{G} \\
\mathbf{I} \\
\mathbf{J} \\
\mathrm{K} \\
\mathrm{L} \\
\mathbf{M} \\
\mathbf{N}\end{array}$ & $\begin{array}{l}520 \\
520 \\
600 \\
500 \\
340 \\
400 \\
650 \\
740 \\
500 \\
485 \\
-\end{array}$ & $\begin{array}{c}++ \\
+ \\
++ \\
6 \\
+ \\
+ \\
+ \\
8 \\
++ \\
12 \\
8.5 \\
10\end{array}$ & $\begin{array}{c}\mathrm{N} \\
+ \\
+ \\
11 \\
\mathrm{~N} \\
\mathrm{~N} \\
++ \\
16 \\
\mathrm{~N} \\
15 \\
13 \\
14\end{array}$ & $\begin{array}{c}10 / 16 \\
1 / 19 \\
1 / 2 \\
1 / 5 \\
2 / 6 \\
6 / 9 \\
1 / 10 \\
1 / 6 \\
12 / 0 \\
6 / 0 \\
1 / 8 \\
1 / 4\end{array}$ \\
\hline
\end{tabular}

The significance of $T$ wave changes is very difficult to determine. Negative $T$ waves have sometimes been associated with a severe right ventricular hypertrophy pattern as judged by $R$ and $R / S$, and in other cases with a similar severe pattern they have remained upright. Sometimes negative $T$ waves have been the sole sign of R.V.H. and have regressed after valvotomy, and sometimes an atypical pattern has been considered to be related to rheumatic myocardial changes.

The probable basis for the difficulties encountered are discussed in this paper and include the varying degrees of left ventricular hypertrophy from associated mitral incompetence or aortic valvular disease and changes secondary to rheumatic myocarditis. In the operation series the evidence for R.V.H. other than electrocardiographic is necessarily presumptive although we are satisfied that the grounds given for presumption are secure. In the post-mortem series there are also difficulties related to ventricular wall thickness and to dilatation and to heart weight and these factors too are discussed. 
TABLE IV

Electrocardiographic Signs of R.V.H. (115 Cases)

\begin{tabular}{|c|c|c|c|}
\hline Direct signs & $\begin{array}{l}\text { Total No. } \\
\text { of cases }\end{array}$ & $\begin{array}{l}\text { Percentage } \\
\text { in which } \\
\text { positive }\end{array}$ & $\begin{array}{c}\text { Sole } \\
\text { criterion }\end{array}$ \\
\hline $\begin{array}{l}\text { Height of } R \\
\mathrm{R}>7 \mathrm{~mm} \text {. in } \mathrm{V} 1 \\
\mathrm{R} / \mathrm{S}>1 \\
\mathrm{R} / \mathrm{S}<1 \\
\mathrm{R}>7 \mathrm{~mm} \text {. in } \mathrm{V} 2^{*} \text { but } \\
\text { not in } \mathrm{V} 1\end{array}$ & $\begin{array}{ll}38 & \\
& 28 \\
& 10 \\
10 & \end{array}$ & $\begin{array}{l}33 \\
12\end{array}$ & $\begin{array}{ll}10 & \\
& 8 \\
& 2 \\
1 & \end{array}$ \\
\hline $\begin{array}{l}R / S \text { ratio } \\
R>S \text { in } V 1 \\
R>S \text { in } V 3 R, V 4 R, \\
\text { or VE } \\
R>S \text { in } V 2 * \text { but } \\
\text { not in V1 }\end{array}$ & $\begin{array}{l}61 \\
76^{* *} \\
3\end{array}$ & $\begin{array}{l}53 \\
80 * *\end{array}$ & $\begin{array}{r}16 \\
0\end{array}$ \\
\hline $\begin{array}{l}\text { V.A.T. } \\
\text { V.A.T. }>0.03 \text { sec. in V1 } \\
\text { V.A.T. in V1 >V5 }\end{array}$ & $\begin{array}{l}62 \\
42\end{array}$ & $\begin{array}{l}54 \\
36\end{array}$ & $\begin{array}{l}0 \\
0\end{array}$ \\
\hline Probable signs & & & \\
\hline $\begin{array}{l}\text { Right B.B.Bl. } \\
\text { Complete } \\
\text { Incomplete } \\
\text { B.B.Bl. in V2 but } \\
\text { not in V1 }\end{array}$ & $\begin{array}{lr}45 & 1 \\
4 & 44\end{array}$ & 39 & $\begin{array}{ll}7 & \\
& 0 \\
& 7 \\
0 & \end{array}$ \\
\hline $\begin{array}{l}\text { Negative } T \text { waves } \\
\mathrm{V} 1 \text { and } \mathrm{V} 2 \\
\mathrm{~V} 1, \mathrm{~V} 2 \text {, and } \mathrm{V} 3\end{array}$ & $\begin{array}{r}49 \\
19 \\
30\end{array}$ & 43 & 7 \\
\hline Indirect signs & & & \\
\hline 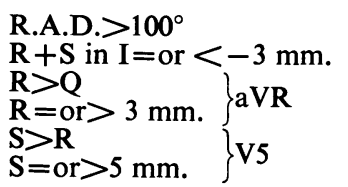 & $\begin{array}{l}40 \\
33 \\
28 \\
42 \\
23 \\
46\end{array}$ & $\begin{array}{l}35 \\
28 \\
24 \\
36 \\
20 \\
40\end{array}$ & $\begin{array}{l}0 \\
0 \\
0 \\
0 \\
0 \\
0\end{array}$ \\
\hline
\end{tabular}

* Recorded over the right ventricle.

** Right-sided V leads were recorded in only 95 of the 115 cases with R.V.H. B.B.Bl.=Bundle branch block. R.A.D.=Right axis deviation. V.A.T.= Ventricular activation time.

FACTORS THAT INFLUENCE THE DEVELOPMENT OF R.V.H.

The cardiac output and the resistance against which the right ventricle must work are the principal factors that influence the development of hypertrophy of the right ventricle. The cardiac output is related to physical activity and to emotion, both of which vary widely in different patients. Young persons in particular are naturally active and in our experience many of the most extreme degrees of R.V.H. come from this group. Others, knowing that heart disease is present and fearing the consequences, or from the discomfort engendered by exertion, lead exceptionally quiet lives and thus limit their cardiac output.

The degree of obstruction at the mitral valve is the most obvious reason for an increase in pulmonary arterial pressure, but not the only one. Pulmonary arteriolar narrowing is a second important factor and seems to vary independently. The size and distensibility of the left atrium also influence the pressure changes that develop in the pulmonary vessels. Post-rheumatic myocardial changes must limit contractility of the right ventricle in many cases, and chemical and 
endocrine changes, about which little is as yet known, are probably more important than at present realized.

The various factors that contribute to R.V.H. are, therefore, neither simple, few, nor mutually unrelated, and account for the variability of R.V.H. in patients with an apparently similar degree of mitral stenosis. It is an old observation that many patients with mitral stenosis, even of severe degree, do not show electrocardiographic signs of R.V.H. In this series of 177 consecutive patients who were considered to be sufficiently disabled for submission to valvotomy, electrocardiographic signs of R.V.H. as detailed above were observed in 115. For reasons discussed above, it was considered probable that some degree of R.V.H. was in fact present in most of them. Admittedly the evidence is presumptive, but the presumption is strong and the inference is supported by postmortem examination in clinically similar cases in whom a full series of cardiograms had been recorded. From the study of our material, it is concluded that electrocardiographic signs do not occur until hypertrophy is marked and that in mitral stenosis hypertrophy is frequently less severe than in congenital heart disease.

The essence of the difference between the two conditions in respect of the cardiographic pattern of R.V.H. is that in pulmonary stenosis an initially healthy muscle has had to overcome a greater resistance for a longer period. In some cases, as discussed in the section on biventricular hypertrophy, the development of the pattern of R.V.H. is prevented by the presence of L.V.H. from mitral incompetence, aortic valvular disease, or essential hypertension.

\section{Difficulties in Post-Mortem Studies}

The difficulties of accurate correlation between electrocardiographic and anatomical findings are not always fully appreciated, and little emphasis has been made regarding this in writing. Tables are available giving the average weight of the heart compared with body weight in healthy subjects of each sex. Many patients with severe mitral stenosis are thin from loss of weight, but it is problematical to what extent heart weight is affected by general loss of body weight.

We have accepted as definite evidence of ventricular hypertrophy a thickness of the muscle on the right of $5 \mathrm{~mm}$. and on the left of $13 \mathrm{~mm}$. for an average body weight of $140 \mathrm{lb}$. (65 Kg.).

It is perfectly clear that when the heart weight considerably exceeds the normal, as it did in most of our post-mortem series, ventricular hypertrophy exists even though the thickness of the ventricular walls is within the accepted normal range. At an ordinary necropsy, even when particular attention is being paid by the pathologist and the physician, it is not practicable to measure accurately by study of X-ray films previously obtained, the degree of dilatation of each chamber, or to make allowances for changes that may have occurred in the few days before death and after cardiograms were recorded.

Individual observers vary in their assessment of the degree of dilatation of the heart chambers in any one case. The maximal thickness of the free ventricular wall can be measured with accuracy, and by careful dissection the contribution of each ventricle to the septum can be determined by weighing. A comparison of heart weights in patients with similar thicknesses of ventricular walls shows, in this series, that the factor of dilatation must be very important. Unfortunately observations are not recorded by different pathologists in a uniform manner and are not always sufficiently precise. For example, one measurement of average ventricular thickness is usually made on each side. In fact ventricular thickness varies considerably from apex to base and the various chest electrodes are clearly placed over ventricular thickness of varying degree. Hypertrophied papillary and trabecular muscles sometimes interfere with accurate measurement of the thickness of the free wall of the ventricle, and the former probably have a definite influence on the cardiographic pattern of ventricular hypertrophy (Kossman et al., 1948).

There is no doubt that the right ventricular patterns accepted do, in fact, reflect anatomical hypertrophy, but the principal problem lies in the large group of patients who have R.V.H. but show no electrocardiographic sign of this. The precise mechanism responsible for the cardiographic changes is unknown. It is difficult to accept the suggestion that they can be related solely to 
changes in the position of the heart resulting from hypertrophy, and it is certain that they are not in direct proportion to the thickness of the ventricular wall beneath the exploring electrode. It may be that hypertrophy of the muscle fibres in the earlier stages does not materially increase the thickness of the ventricular wall but may yet affect the changes in electrical potential responsible for the electrocardiographic pattern. The mechanism by which dilatation affects the cardiogram and produces the so-called "strain pattern" is likewise not known, nor is it clear how rheumatic myocarditis affects the development of the hypertrophy pattern.

All these considerations make it quite impossible accurately to compare pathological and electrocardiographic findings. Nevertheless it can usually be decided whether R.V.H. does or does not exist and its approximate severity.

\section{BivenTRICUlAR HYPERTROPHY}

From studying published papers and our own material we consider that biventricular hypertrophy may be diagnosed when (1) there are signs of L.V.H. and of R.V.H., a combination that is said to be unusual but was found in 4 of our patients, or (2) signs of L.V.H. and of pronounced clockwise rotation, as shown by $R>Q$ in aVR and $S>R$ in V5 and with inversion of $T$ in V1.

Signs of L.V.H. with a vertical position of the heart are considered highly suggestive of combined hypertrophy. Signs of L.V.H. with inversion of T wave in V1 are considered suggestive, and with inversion of $\mathrm{T}$ wave in V1 and V2 very suggestive, of combined hypertrophy. Electrocardiographic signs of R.V.H. with a horizontal heart can occur in the absence of L.V.H. This combination of signs does not indicate biventricular hypertrophy and we have one case illustrating this point.

In the operation series, predominant mitral incompetence was present in 23 cases, aortic incompetence in 60, aortic stenosis in 3, and diastolic hypertension (B.P. $>160 / 100$ ) in 15 , but in only 4 cases were there electrocardiographic signs of biventricular hypertrophy.

In the post-mortem series there were 22 cases with anatomical hypertrophy of both ventricles. In 11 of these the cardiographic signs were of isolated R.V.H. and in 2 of isolated L.V.H., but 6 did not show cardiographic signs of ventricular hypertrophy, and only 3 showed signs of biventricular hypertrophy. A detailed analysis of this material shows that considerable anatomical biventricular hypertrophy can occur in association with cardiograms showing R.V.H. alone or without evidence of R.V.H. or L.V.H. In two cases with L.V.H. signs alone in the cardiogram the anatomical L.V.H. was proportionately greater than the R.V.H., and the former seemed to be masking the cardiographic signs of R.V.H. It is probable that from the electrical point of view the signs of R.V.H. and of L.V.H. frequently balance each other and consequently no ventricular hypertrophy signs appear in the cardiogram. However, our cases indicate that there is no obvious relationship between the degree of hypertrophy in each ventricle and the presence or degree of cardiographic signs of biventricular hypertrophy.

It is concluded that electrocardiographic signs of combined ventricular hypertrophy are uncommon in patients with rheumatic heart disease, even though pathological examination shows that such hypertrophy may be considerable. From a practical point of view, in differential diagnosis of the relative importance of mitral stenosis and of mitral incompetence when both defects are present, electrocardiographic evidence of biventricular hypertrophy signifies that the degree of mitral incompetence is such that thoracotomy with a view to undertaking mitral valvotomy is not advisable. Predominant mitral incompetence associated with a high pulmonary vascular resistance and direct cardiographic signs of R.V.H. is uncommon. In relation to the problem of mitral stenosis associated with aortic valvular disease, the severity of the latter must be assessed on the signs in the peripheral arteries, and of the former on evidence pointing to substantial pulmonary hypertension in the absence of left ventricular failure. Cardiac catheterization may provide decisive evidence in favour of predominant mitral disease by revealing considerable pulmonary hypertension. Biventricular hypertrophy in the cardiogram due to associated aortic valvular disease is not necessarily a contra-indication to mitral valvotomy, because right mitral stenosis may be present. 


\section{LEFT VENTRICULAR HYPERTROPHY}

We have not made a definitive study of L.V.H. in rheumatic heart disease. The recognition of L.V.H. in patients with signs of mitral stenosis who are under consideration for surgical treatment is however very important because it invariably means that some significant complication is present. An accepted pattern of L.V.H. used to be left axis deviation in the standard limb leads with depression of the $S-T$ segment and a low or negative $T$ wave in lead $I$ and such a pattern certainly points to the need for a more complete cardiographic study. Since the introduction of unipolar præcordial leads there is general agreement that the pattern of a tall $\mathrm{R}$ wave with depression of the $\mathrm{S}-\mathrm{T}$ segment and a low or negative $T$ wave in leads recorded over the left ventricle is a more reliable indication of L.V.H.

It is, however, difficult to be sure of absolute values for the height of $R$ as explained (see page 468) and digitalis frequently affects the ST-T segment, the changes persisting for some weeks after administration has ceased. Sokolow and Lyon (1949) accept the following as absolute criteria for the diagnosis of L.V.H. in V5 or V6: $(a)$ voltage of $\mathrm{R}>26 \mathrm{~mm}$.; $(b)$ depression of S-T segment $>0.5 \mathrm{~mm}$.; (c) a flat, diphasic, or inverted $\mathrm{T}$ with a normal $\mathrm{R}$ and small $\mathrm{S}$ and $\mathrm{S}-\mathrm{T}$ depression $>0.5 \mathrm{~mm}$.; $(d)$ V.A.T. $=0.06 \mathrm{sec}$. or more, especially when associated with a tall $\mathrm{R}$ wave.

Our findings are similar to those of Leatham in that the amplitude of $\mathrm{R}$ over the left ventricle in health may be more than $26 \mathrm{~mm}$. There is room for further study on large numbers of cases but we consider there is usually a much wider variation in the height of $R$ over the left than over the right ventricle and consequently an absolute standard cannot be reached.

Mitral Incompetence. When the physical signs of associated mitral stenosis and incompetence are accompanied by cardiographic signs of L.V.H. this signifies that the incompetence is predominant and the patient unsuitable for valvotomy, if aortic valvular disease and systemic hypertension can be excluded as important factors. There has been no exception to this rule. Free mitral incompetence may, however, occur with normal cardiograms even when there is clinical and radiological evidence of left ventricular enlargement.

Aortic Valvular Disease and Systemic Hypertension. Electrocardiographic evidence of L.V.H. from aortic stenosis or incompetence or from systemic hypertension is not in itself a contra-indication to mitral valvotomy, if other evidence points to severe mitral stenosis being present in addition.

\section{ISCHEMIC PATTERNS}

In some patients, transient $\mathrm{S}-\mathrm{T}$ depression and flattening of the $\mathrm{T}$ wave has been observed during an attack of pulmonary œdema induced by tachycardia secondary to the emotion of examination for possible operation or from the exertion of coming up to hospital (Fig. 15). On occasion similar changes have been induced by an exercise test undertaken to try and determine the nature of a complaint of pain in the chest in a patient with mitral stenosis. In none of these patients was digitalis a possible factor in the genesis of the ST-T changes. Pain did not accompany any of the incidents during which these cardiographic changes were recorded. The cardiographic patterns differed from those of "ventricular strain" in that S-T depression of abnormal degree was the prominent change, whereas in the latter, the cardinal feature is $T$ inversions often without any ST-T shift. Furthermore S-T depressions were not confined to right ventricular leads. In the strain pattern the $\mathrm{T}$ inversions occur only over the right ventricle.

In a patient with severe mitral disease and tachycardia and acute pulmonary œdema, coronary blood flow may be inadequate for muscle requirements during the episode and the electrocardiographic changes resemble those seen in the left ventricular chest leads during exercise or during an attack of angina pectoris in patients with coronary artery disease.

\section{The Practical Value of Electrocardiography in the Assessment OF PATIENTS FOR VALVOTOMY}

Just as absolute reliance can rarely be placed on a single physical sign, so in regard to special methods of investigation there are few absolute rules. Nevertheless, we consider that the cardio- 


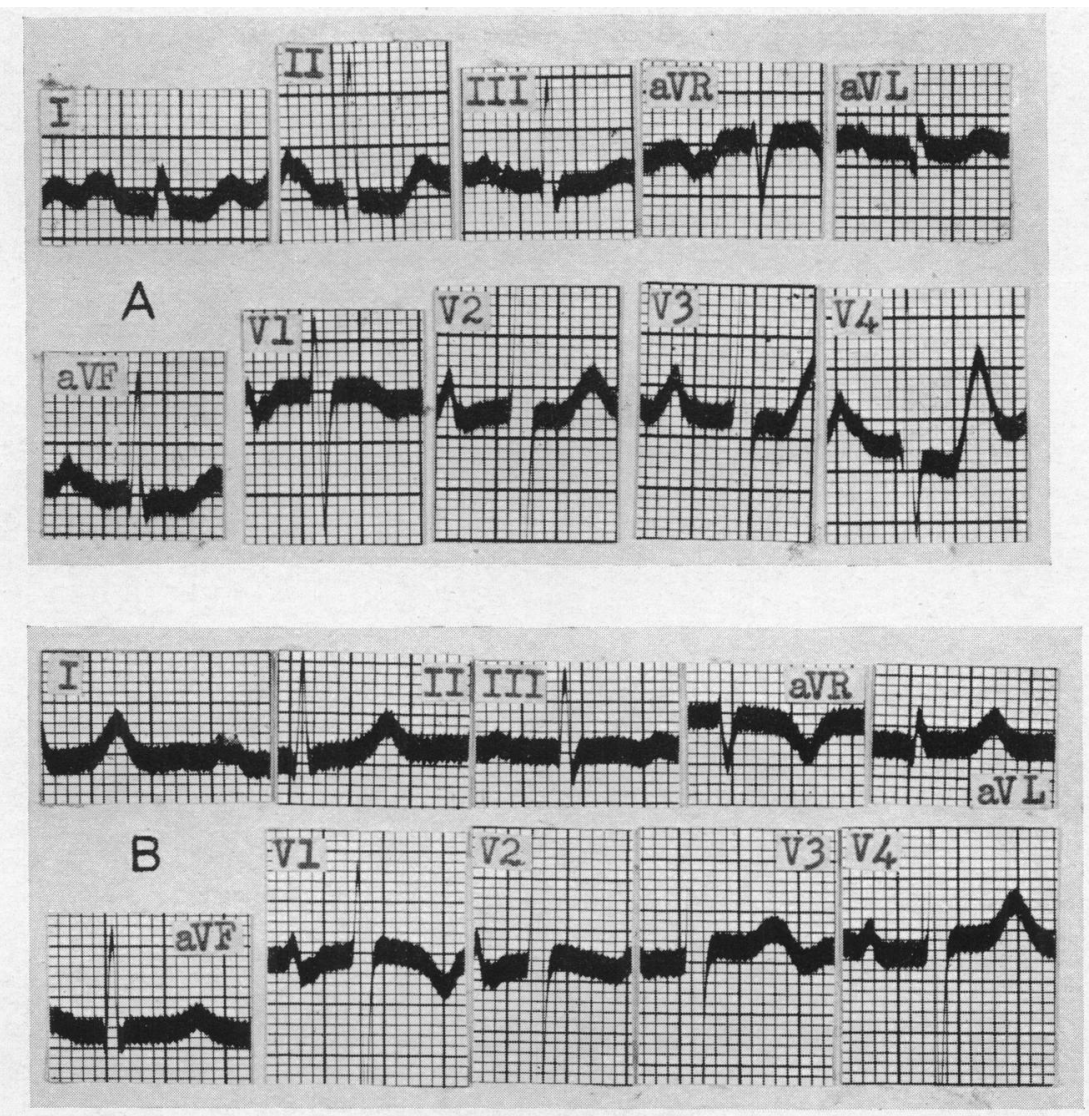

FIG. 15.-(A) Recorded during an attack of acute pulmonary œdema, showing S-T depression in I, II, VF, V2, V3, V4. (B) Recorded a day later, showing disappearance of S-T changes, the pattern being the same as that recorded before the pulmonary œdema developed.

gram may give useful information in the assessment of patients with rheumatic valvular disease especially in relation to operative treatment. The finding of an entirely normal cardiogram suggests that symptoms may be out of proportion to the real physical disability and if doubt exists on other grounds as to the necessity for operation cardiac catheterization may give useful guidance. Tight mitral stenosis may be associated with a normal electrical axis but the greater the degree of right axis deviation the more likely is R.V.H. to be present. Left axis deviation suggests that some significant complications may be present and other evidence for this should be sought.

In our experience, other things being equal, R.V.H. is a strong indication for considering surgical treatment because it usually signifies considerable pulmonary hypertension and a poor progńosis. Tight mitral stenosis is the usual cause but occasionally severe pulmonary hypertension is associated with predominant mitral incompetence and this possibility should be remembered and the other evidence reviewed with particular care.

The cardiogram may provide objective evidence of progression or regression of ventricular hypertrophy.

Signs of biventricular hypertrophy always mean that some important complication is present. L.V.H. from mitral incompetence is a contra-indication to operation for valvotomy but when due to associated aortic valvular disease severe mitral stenosis may be present in addition and the relative importance of each defect must be assessed on other grounds. 
Cardiograms may be useful in recording an ischæmic pattern during an attack of dyspnœa or tachycardia and this finding constitutes an urgent need for valvotomy.

\section{SUMmaRY AND CONCLUSIONS}

An electrocardiographic study of mitral valvular disease has been made in a series of 200 consecutive patients subjected to surgical treatment and in 38 post-mortem cases. In all detailed clinical radiological, and usually cardiac catheterization findings were available.

Standard and augmented unipolar limb leads together with leads V1-7 and CR1 were taken in the 200 operation cases and 36 of the 38 post-mortem cases. In addition, right-sided V leads were recorded in 141 of the operation cases. The following points were studied: axis deviation; the algebraical sum of $\mathrm{R}+\mathrm{S}$ in lead $\mathrm{I}$; the electrical position of the heart; $\mathrm{P}$ waves; $\mathrm{Q}-\mathrm{T}$ and $\mathrm{P}-\mathrm{R}$ intervals; absolute height of $\mathrm{R}$ and depth of $\mathrm{S}$ and the $\mathrm{R} / \mathrm{S}$ ratio in the præcordial leads; $\mathrm{Q}$ waves; height of $R$ and $R / Q$ ratio in aVR; flattening or inversion of $T$ and depression of $S-T$ segment in præcordial leads; ventricular activation time; and the patterns of right bundle branch block.

The amount of useful information obtainable from the standard limb leads is limited. Although they do not provide a diagnostic pattern of R.V.H., indirect signs are frequently present and occasionally they provide the sole suggestive sign. Broad or bifid $\mathbf{P}$ waves of a type strongly suggesting mitral disease occurred in 92 per cent of the 115 patients in sinus rhythm. The duration of the QT $c$ and P-R intervals did not provide reliable evidence of rheumatic activity.

The heart was vertical or semi-vertical in position in 90 per cent of patients with predominant mitral stenosis. When the heart was horizontal or semi-horizontal in position some factor complicating mitral stenosis was usually present.

Signs of R.V.H. were present in 89 per cent of cases with right axis deviation of $100^{\circ}$ and in 100 per cent of cases in which the algebraical sum of $R+S$ in lead I was negative by 3 or more, in 89 per cent in which $\mathrm{R}=3 \mathrm{~mm}$. or more in aVR, in 89 per cent in which $\mathrm{S}=5 \mathrm{~mm}$. or more in - V5, and in 100 per cent in which $R>Q$ in aVR or $S>R$ in V5. Although changes indicating R.V.H. were commonly sought in V1, it is shown that sole or stronger evidence may be found in V2 or in the right-sided V leads (V3R, V4R, or VE). An absolute height of $R>7 \mathrm{~mm}$. in V1(2) or an R/S ratio $>1$ in leads recorded over the right ventricle almost certainly signifies R.V.H.

Complete or incomplete right bundle branch block, or a negative T in V1 and in V2 or CR1 are probably signs of R.V.H. in patients with rheumatic heart disease. The possibility of negative $T$ waves resulting from myocardial fibrosis is discussed. A ventricular activation time $>0.03 \mathrm{sec}$. is accepted as a sign of R.V.H. but in this series never occurred as a sole sign and is therefore of no practical value. Depression of the S-T segment may be found when other signs of R.V.H. are well marked. Transient depression may be due to ischæmia.

Electrocardiographic signs do not develop until the anatomical degree of R.V.H. is considerable. The relative importance of the various electrocardiographic signs of R.V.H. is discussed and reasons are given for concluding that in rheumatic heart disease it is not possible to grade the degrees of severity.

Brief reference is made to factors that influence the development of the R.V.H. pattern and difficulties in post-mortem studies are discussed. Justification for the electrocardiographic criteria of R.V.H. accepted rests on presumptive evidence based on clinical, radiological, and catheterization studies; regression of the various patterns following valvotomy and post-mortem correlation. Published criteria for the electrocardiographic diagnosis of R.V.H. are reviewed.

In this series an electrocardiographic diagnosis of R.V.H. was made in 115 of 176 patients (65\%) in whom the presence of predominant mitral stenosis was confirmed at operation and in one patient with predominant incompetence. The detection of the electrocardiographic pattern for R.V.H. is important because it usually signifies that there is considerable pulmonary hypertension and that unless improvement can be obtained by operation the outlook is poor. In the great majority of cases of rheumatic heart disease, R.V.H. is secondary to tight mitral stenosis but occasionally when 
pulmonary resistance is high R.V.H. may be found in association with predominant mitral incompetence.

Evidence of pre-operative progression or post-operative regression of R.V.H. may be recorded.

Criteria for the diagnosis of biventricular hypertrophy are discussed and it is concluded that cardiographic evidence of combined hypertrophy is important although uncommon even when anatomical bi-hypertrophy is considerable. When due to mitral incompetence, valvotomy for associated stenosis is not indicated but when due to aortic valvular disease or to systemic hypertension signs of biventricular hypertrophy do not necessarily indicate that tight mitral stenosis is not present in addition. Signs of L.V.H. invariably mean some important complication is present but likewise do not exclude the existence of severe mitral stenosis.

Finally, it must be concluded that there is no absolute electrocardiographic sign of R.V.H. because occasionally exceptions have been found or recorded for every criterion.

We have much pleasure in acknowledging the assistance given by Mr. Raymond Allford, A.S.C.T., F.S.T.A., Senior Technician; Miss A. Malcolm, A.S.C.T., and Miss S. Crawford, A.S.C.T. of the Cardiac Department, Western General Hospital, Edinburgh, for their meticulous work in recording the electrocardiograms in this series. We are also indebted to Mr. Derry Wright, Technician, Department of Medicine, University of Edinburgh, for his help in preparing the electrocardiographic illustrations in this paper.

\section{REFERENCES}

Ashman, R., and Hull, E. (1941). Essentials of Electrocardiography. 2nd ed., The MacMillan Co., New York.

Barker, J. M., and Valencia, F. (1949). Amer. Heart J., 38, 376.

Berliner, K., and Masters, A. M. (1938). Arch. intern. Med., 61, 39.

Burch, G., and Winsor, T. (1949). A Primer of Electrocardiography. 2nd ed., Lea \& Febiger, Philadelphia.

Carouso, G. J., Maurie, P., Scelat, L., and Lenegre, J. (1951). Arch. Mal. Coeur, 44, 769.

Criteria Committee of the New York Heart Association. Nomenclature and Criteria for Diagnosis of Diseases of the Heart. (1953). 5th ed., New York Heart Association, New York.

Dieuaide, F. R. (1921). Arch. intern. Med., 27, 558.

Donzelot, E., Metianu, C., Durand, M., Cherchi, A., and Vlod, P. (1951). Arch. Mal. Coeur, $44,97$.

Goldberger, E. (1945). Amer. Heart J., 30, 341. (1953). Unipolar Lead Electrocardiography. 3rd ed., Henry Kimpton, London.

Graybiel, A., White, P. D., Wheeler, L., and Williams, C. (1952). Electrocardiography in Practice. 3rd ed., W. B. Saunders, Philadelphia.

Herrman, G. R., and Wilson, F. N. (1921). Amer. Heart J., 9, 91.

Kossman, C. E. (1953). Circulation, 6, 920.

- , Berger, A. R., Brumlik, J., and Briller, S. A. (1948). Amer. Heart J., 35, 309.

Leatham, A. (1950). Brit. Heart J., 12, 213.

Lewis, T. (1913). Clinical Electrocardiography. Shaw \& Sons, London.

McGregor, M. (1950). Brit. Heart J., 12, 351.

Myers, G. B., Klein, H. A., and Stofer, B. E. (1948). Amer. Heart J., 35, 1.

$\longrightarrow,-\longrightarrow$, and Hiratza, T. (1947). Amer. Heart J., 34, 785.

Pagnoni, A., and Goodwin, J. F. (1952). Brit. Heart J., 14, 451.

Reynolds, G. (1953). Brit. Heart J., 15, 250.

Sokolow, M., and Friedlander, R. D. (1949). Amer. Heart J., 38, 665.

- and Lyon, T. P. (1949a). Amer. Heart J., 37, 161.

,- , $(1949 b)$. Amer. Heart J., 38, 273.

Taran, L. M., and Szilagyi, N. (1947). Amer. Heart J., 33, 14.

Wilson, F. N., Johnston, F. D., Rosenbaum, F. F., and Barker, P. S. (1946). Amer. Heart J., $32,277$. Amer. Heart J., 27, 19.

- Rosenbaum, F. F., and Johnston, F. D. (1947). “Ventricular Complex of the Electrocardiogram." In Advances in Internal Medicine, Vol. II, Interscience Press, New York.

Woods, A. (1952). Brit. Heart J., 14, 193. 